
\title{
28 Research Suare \\ Performance of Daily Satellite-Based Rainfall in Groundwater Basin of Merapi Aquifer System, Yogyakarta
}

Novi Rahmawati ( $\square$ novira.wati@gmail.com )

Universiteit Twente Faculteit Geo-Informatie Wetenschappen en Aardobservatie https://orcid.org/00000003-2294-4507

Kisworo Rahayu

Serayu Opak River Basin Organization

Sukma Tri Yuliasari

Bureau of Geophysics, Meteorology and Climatology

\section{Research Article}

Keywords: satellite-based rainfall, Merapi Aquifer System Rainfall, CHIRPS, GPM IMERG, CMORPH, TRMM

Posted Date: June 14th, 2021

DOI: https://doi.org/10.21203/rs.3.rs-490280/v1

License: (c) (1) This work is licensed under a Creative Commons Attribution 4.0 International License. Read Full License

Version of Record: A version of this preprint was published at Theoretical and Applied Climatology on July 23rd, 2021. See the published version at https://doi.org/10.1007/s00704-021-03731-9. 


\section{Abstract}

Evaluation of the performance of daily satellite-based rainfall (CMORPH, CHIRPS, GPM IMERG, and TRMM) was done to obtain applicable satellite rainfall estimates in groundwater basin of Merapi Aquifer System (MAS). Performance of satellite data was assessed by applying descriptive statistics, categorical statistics, and bias decomposition on the basis of daily rainfall intensity classification. This classification is possible to measure the performance of daily satellite-based rainfall in much detail.

$\mathrm{CM}(\mathrm{CMORPH})$ has larger underestimation compared to other satellite-based rainfall. This satellite-based rainfall also mostly has the largest RMSE, while CHR (CHIRPS) is the lowest. CM has a good performance to detect no rain, while IMR (GPM-IMERG) has the worst performance. IMR and CHR have a good performance to detect light and moderate rain. Both of them have larger $H$ frequencies and lower $M B$ values compared to other satellite products. CHR mostly has a good performance compared to TR (TRMM) especially on wet periods. CM, IMR, and TR mostly have a good performance on dry periods, while $\mathrm{CHR}$ on wet periods. $\mathrm{CM}$ mostly has the largest $M B$ and lowest $A H B$ values. $\mathrm{CM}$ and $\mathrm{CHR}$ have better accuracy to estimate rain amount compared to IMR and TR. All in all, all 4 satellite-based rainfall has large discrepancy compared with rain gauge data along mountain range where orographic rainfall usually occurs in wet periods. Hence, it is recommended to evaluate satellite-based rainfall with time series of streamflow simulation in hydrological modeling framework by merging rain gauge data with more than one satellite-based rainfall except to merge both IMR and TR together.

\section{Introduction}

Ground rainfall estimates using rain gauges is a traditional way of the most common methods (Brauer et al. 2016) that is used to correct the bias of satellite rainfall estimates (Ma et al. 2019; Park et al. 2019) for water resources application and related studies. For example, it is as the input for hydrological modeling in basin scale (Andersen et al. 2001) and for modeling base flow (Becker and Braun 1999). Bias correction requires ground rainfall estimates to correct satellite rainfall estimates because the finer ground observation can reduce an error in spatial precipitation gradients of satellite rainfall estimates (Zhang and Anagnostou 2019). The optimal and appropriate satellite rainfall estimates should be selected before they are corrected with ground rainfall estimates.

It is necessary to evaluate the performance of satellite rainfall estimates to limit the error and uncertainty of corrected gridded rainfall estimates when it is merged to the ground rainfall estimates. It is because the successful of bias correction depends on understanding and quantification of systematic uncertainties inherent to satellite-based rainfall and sensors (Sorooshian et al. 2011). The evaluation of satellite-based rainfall performance will show the consistency and deficiencies of satellite rainfall estimates (Pfeifroth et al. 2015) compares to ground observation (Sorooshian et al. 2011). Ground observation of rain gauge measures rainfall directly, while satellite rainfall products estimate rainfall from visible/infrared (VIS/IR), microwave MW), and/or radar sensors (Bai and Liu 2018). Satellite observing 
system also has a complex uncertainty and error because of precipitation estimates from cloud and precipitation parameters (Stephens and Kummerow 2007).

Satellite rainfall estimates CMORPH (Climate Prediction Center Morphing Methods) is passive microwave (PMW)-based rainfall estimates (Joyce et al. 2010) that accurately derives rainfall estimates compare to infrared (IFR)-based algorithm (Ebert et al. 2007). CMORPH is applicable for diurnal cycle of precipitation (Janowiak et al. 2005) in mountainous region in Bali compared to other satellite-rainfall estimates (Rahmawati 2020), although CMORPH tends to underestimate heavy rain-rate in mountainous area (Derin et al. 2016; Rahmawati 2020; Rahmawati and Lubczynski 2018). This satellite can be used to evaluate its performance in groundwater basin in Merapi Aquifer System since it is more accurate in tropics island of Bali compared to TRMM (The Tropical Rainfall Measuring Mission) and PERSIANN (Precipitation Estimation from Remotely Sensed Information using Artificial Neural Networks). Satellite rainfall estimates of CHIRPS (Climate Hazards group Infrared Precipitation with Stations) has a finer spatial resolution that has probability to catch diurnal cycle of precipitation in tropics. Satellite Rainfall estimates of IMERG (Integrated Multi-satellitE Retrieval for GPM or Global Precipitation Measurement) is the latest replacement of TRMM mission. It considers to bring together existing satellite rainfall estimates of CMORPH, TRMM and PERSIANN (Rozante et al. 2018). It is necessary to evaluate the performance of both CHIRPS and GPM-IMERG in groundwater basin of Merapi Aquifer System. Moreover, the performance of TRMM is also possible to be evaluated its performance in MAS as a control point to be able to know the possible improvement of GPM-IMERG.

Merapi Aquifer System (MAS) is a groundwater basin in Yogyakarta that abundance with richness of groundwater storage. This basin has physical border of mountain range that separates Java Island into two parts, northern and southern. There is the line of water body of Hindia Ocean that borders groundwater basin of MAS in the south part. The border in the east part is Gunung Sewu Mountain Range, while ancient volcano of Kulon Progo in the west part. This physical border of MAS is leading to the unique character of rainfall pattern and distribution in this area. The sufficient information of precipitation from rain gauge and satellite-based rainfall is necessary to be able to describe this unique character. Therefore, the objectives of the research is to evaluate the performance of daily satellite-based rainfall on the basis of 13 rain gauges over 5 year periods ( 1 January 2008-31 December 2012) applying descriptive statistics, categorical statistics, and bias decomposition at various class of rainfall intensity.

The novelty of the research is in the first time : (i) validation of satellite rainfall estimates over MAS using 4 satellite-based rainfall, i.e. CMORPH, CHIRPS, GPM IMERG, TRMM (ii) latest and long periods of validation, i.e. recent year of 2008 to 2012 and over 5 years, (iii) different assessment of rainfall intensity of satellite rainfall estimates applying descriptive statistics, categorical statistics, and bias decomposition.

\subsection{Study Area Description}

Yogyakarta Special Region is located in the south of Central Java Province, Indonesia. In the north, it is bordered with mountain range that separates Java Island into two parts, northern and southern. 
Yogyakarta Special Region is situated in the southern part of mountain range with Merapi Volcano as part of this mountain range. Top of Merapi Volcano is the highest places in Yogyakarta Special Region that is 2,925 m.asl based on topography map scale 1:25,000 in 1998 (Fig. 1). Only the south slope of Merapi Volcano is as the part of Yogyakarta Special Province, others are under administrative of Central Java Province. Most of Yogyakarta Special Province areas abundance with richness of groundwater storage because it is included in Merapi Aquifer System.

Based on rainfall data on 1 January 2008 to 31 December 2012 within 13 rain gauges stations available in MAS, the maximum daily rainfall is $188.0 \mathrm{~mm} \cdot$ day $^{-1}$. This rainy events is classified as extreme rain. Most of rainfall occurs with the intensity $\leq 20 \mathrm{~mm} \cdot$ day $^{-1}$ and $20-50 \mathrm{~mm} \cdot$ day $^{-1}$ which are light to moderate rain. Very heavy rainfall or rainfall with the intensity of 100 to $150 \mathrm{~mm} \cdot$ day $^{-1}$ occurs very rarely. Only occurs in a certain day or some days for a year in certain station. This very heavy rainfall is not only occurs in high land areas, but also in lowland areas. It is probably because the condition of MAS that is surrounded and blocked by mountain range and sea. Extreme rain only occurs twice within 5 years.

\section{Methods}

The time span to evaluate satellite daily rainfall estimates in Merapi Aquifer System (MAS) is on 1 January 2008 until 31 December 2012 (1,826 days). The data collection is from Serayu Opak River Basin Organization (locally called BBWS Serayu Opak), Yogyakarta. Rainfall data is measured with automatic and non-automatic rain gauges station. The automatic rain gauge measurement is mostly used to validate rainfall estimates. In case the automatic measurement is broken for several months or year the manual rain data is used for validation. There are 13 daily gauge stations within Merapi Aquifer System used to validate satellite rainfall estimates of CMORPH, CHIRPS, GPM IMERG and TRMM (Fig. 1). These 13 gauges is selected because they have complete data. The type of the gauge is tipping bucket rain gauge that accumulates a volume in a small bucket corresponding to $0.1 \mathrm{~mm}$ (Michaelides et al. 2009). There are also 6 climatology stations (wind gauges) used to analyze daily wind speed in MAS (Fig 1). ArcGIS is used for processing, analyzing and finalization of MAS rainfall estimates with the support of Python GUI (IDLE) and R Software.

Satellite data of 8-minutes CMORPH is resampled on daily basis for the same period with rain gauge observation data in Yogyakarta Special Region. The 8-minutes CMORPH (CM) has 0.07区 spatial resolution (roughly $8 \mathrm{~km} \times 8 \mathrm{~km}$ at equator). This finer resolution can capture rainfall dynamic compared to coarser resolution in diurnal cycle of tropical rainfall in Indonesia (Rahmawati and Lubczynski 2018). CMORPH is merged of Infrared (IR) and microwave (MW) applying lagrangian equation to retrieve rainfall estimates (Joyce et al. 2004). This rainfall product does not use rain gauge data for rainfall retrieval. There is no adjustment with rain gauge data to obtain rainfall estimates of $\mathrm{CMORPH}$. The version used in this paper is purely from satellite sensors (Xie et al. 2017). It is not only because it is best performance in Bali Island (Rahmawati 2020), but also it shows improvement performance of a satellite-only product. The poor quality and the lack of spatial representative of that gauges that are used for bias correction are probably the reason satellite-only product have a good performance in rainfall estimates compared to 
satellite-gauge bias corrected product (Habib et al. 2014). The data of CMORPH or CMORPH version 0.x is downloaded with the support of ILWIS ISOD Toolbox (Maathuis et al. 2014).

The GPM IMERG satellite data is multi satellite algorithms from the component of TRMM TMPA, CMORPH-KF, PERSIANN-CCS (Huffman et al. 2019). This is gridded rainfall estimates product that GPMCO (GPM Core Observatory) and its partners of satellite precipitation estimates along with geostationary IR sensors to fill the gaps between MW sensors by lagrangian time interpolation or lagrangian morphing and monthly precipitation data. GPM-CO uses the most advanced precipitation sensors in space currently. It is the precipitation sensors successors of TRMM (Hou et al. 2014). GPM IMERG (IMR) provides a quasi-global satellite rainfall estimates from $60 \otimes \mathrm{N}$ to $60 \otimes \mathrm{S}$. It is available in gridded of $0.1 \rrbracket$ spatial resolution (roughly $10 \mathrm{~km} \times 10 \mathrm{~km}$ at equator) and 30 minutes temporal resolution ( 0 and Kirstetter 2018; Skofronick-Jackson et al. 2018). The datasets is downloaded on daily basis from 1 January 2008 to 31 December 2012 using this

link https://gpm1.gesdisc.eosdis.nasa.gov/data/GPM_L3/GPM_3IMERGDF.06. In this research, we use the final run and current version of GPM IMERG that is the version 06. It is because this version has (i) inclusion of additional sensors specifically of TRMM, (ii) parent GPM product improvement, and (iii) the refinement of morphing components (Freitas et al. 2020).

TRMM TMPA 3B42 version 7 is bias-corrected satellite rainfall product of TMPA (Guo et al. 2015). It is the merged product of Infrared from geosynchronous satellite and passive microwave from low orbit satellite. It covers between coverage of $50 \otimes \mathrm{N}$ to $50 \otimes \mathrm{S}$. It is available in gridded of $0.25 \bigotimes$ spatial resolution (about $27 \mathrm{~km} \times 27 \mathrm{~km}$ at equator) and 3-hours temporal resolution. TRMM (TR) and GPM are used to characterize the changes of earth water cycle, freshwater fluxes and reservoirs, and to advance the prediction of natural disaster and extreme weather (Skofronick-Jackson et al. 2018). The webpage to obtain daily temporal resolution of this data is https://disc2.gesdisc.eosdis.nasa.gov/data/TRMM_L3/TRMM_3B42_Daily.7.

CHIRPS satellite data is a quasi-global rainfall data that is available from $50 \varangle \mathrm{N}$ to $50 \varangle \mathrm{S}$ and $180 \otimes \mathrm{E}$ to $180 \otimes W$ coverages (Aksu and Akgül 2020). This datasets is available since 1981 to present (Sacré Regis M. et al. 2020). CHIRPS (CHR) is high resolution of satellite observation and imagery that provides shorted low latency, high resolution, low bias, and long period of precipitation gridded datasets for drought monitoring and climate change analysis (Funk et al. 2015; Liu et al. 2019). The source of CHIRPS satellite rainfall estimates is from monthly precipitation data, geostationary satellite thermal IR observation, TRMM 3B42, and in-situ precipitation observation (Funk et al. 2014). CHIRPS is available for $0.05 \bigotimes$ spatial resolution (about $5 \mathrm{~km} \times 5 \mathrm{~km}$ at equator) and daily temporal resolution. The datasets are available in this link https://data.chc.ucsb.edu/products/CHIRPS-2.0/global_daily/tifs. The datasets is downloaded with the same period with ground rainfall estimates from rain gauge.

The performance of 4 satellite-based rainfall was assessed applying descriptive statistics, categorical statistics and bias decomposition adapting Rahmawati and Lubczynski (2018). The modification is performed by the assessment of satellite-based rainfall applying 4 rainfall intensity classification 
adapting from BMKG (2010). It is done so that it is to be able to evaluate the performance of satellite rainfall estimates in much detail in each rainfall classification. Most of rainfall intensity occurs from light to moderate rain so that rainfall intensity from heavy to extreme is categorized as one classification. The modification of rainfall intensity classification is shown in Table 1. The formula for descriptive statistics consists of mean error $(M E)$, root mean square error (RMSE) as is shown in Equations 1 and 2. The assessment was performed for each station in each season division separately. Since satellite-based rainfall is not good performance in transition season in tropics climate of Bali (Rahmawati 2020) so that the division of season were based on assumption: i). wettest months in wet period (January to March or Jan-March), ii). wet months in wet period (October to December or Oct-Dec), iii). dry months in dry period (April to June or Apr-Jun) and iv). driest months in dry period (July to September or Jul-Sep). The representative and different location of stations will be assessed to evaluate the performance of satellitebased rainfall in much detail. These selected rain gauges stations is shown in Fig. 1.

$$
\begin{aligned}
& M E=\frac{1}{T} \sum_{t=1}^{T}\left(R s_{t}-R g_{t}\right) \\
& R M S E=\sqrt{\frac{1}{T} \sum_{t=1}^{T}\left(R s_{t}-R g_{t}\right)^{2}}
\end{aligned}
$$

Equation 1

Equation 2

In Equations 1 to 2, $T$ is total number of daily rainfall events in each rainfall intensity classification from 2008 to 2012 (i.e, $T$ is number of days for $0 \mathrm{~mm} \cdot$ day $^{-1}$ (no rain) for January to March from 2008 to 2012), $R s_{t}$ is the value of rainfall based on satellite-based rainfall at time series $t, R g_{t}$ is the value of rainfall based on rain gauge at time series $t$.

Categorical statistics and bias decomposition are also classified based on rain intensity. Categorical statistics and bias decomposition were calculated for each 13 available rain gauges. Contingency table for categorical statistics is expressed in Table 2, while the formula for bias decomposition is shown in Equations 3-7 adapting from Rahmawati and Lubczynski (2018). The contingency table in Tables 2 shows the example of contingency table for zero rain $\left(0 \mathrm{~mm} \cdot \mathrm{day}^{-1}\right)$ and light rain $\left(0 \mathrm{~mm} \cdot \mathrm{day}^{-1}<\right.$ rain $<20$ $\mathrm{mm} \cdot$ day $\left.^{-1}\right)$, others rainfall intensity class is following this example. The performance of satellite-based rainfall for categorical statistics in detecting no rain is assessed from $C N$ and $F A$, while for rainfall intensity $>0 \mathrm{~mm} \cdot \mathrm{day}^{-1}$, i.e. light rain to extreme rain, is assessed from $H$ and $M$. In bias decomposition, the assessment of no rain detection is based on $R s$ (or it is equal to $T B$ for no rain since only $F B$ available), while $A H B$ and $M B$ is for rainfall intensity $>0 \mathrm{~mm} \cdot$ day $^{-1}$ (light to extreme rain).

where $F A$ is when satellite-based rainfall detects rainfall and rain gauge detects no rainfall, $C N$ is when both satellite-based rainfall and rain gauge detects no rainfall, $H$ is the daily event when both satellite- 
based rainfall and rain gauge detects rainfall, and $M$ is when satellite-based rainfall detects no rainfall and rain gauge detects rainfall

$$
\begin{array}{ll}
H B=\sum_{t=1}^{T}\left(R s_{\mathrm{t}}-R g_{\mathrm{t}}\right) & \text { Equation 3 } \\
A H B=\sum_{\mathrm{t}=1}^{T}\left|R s_{\mathrm{t}}-R g_{\mathrm{t}}\right| & \text { Equation 4 } \\
M B=\sum_{\mathrm{t}=1}^{T}\left(R g_{t}\right):\left(R s_{t}=0 ; R g_{\mathrm{t}}>0\right) & \text { Equation 5 } \\
F B=\sum_{\mathrm{t}=1}^{T}\left(R s_{t}-R g_{t}\right):\left(R s_{t}>0 ; R g_{\mathrm{t}}=0\right) & \text { Equation 6 } \\
T B=H B+M B+F B & \text { Equation 7 }
\end{array}
$$

where $H B$ is hits bias, $A H B$ is absolute hits bias, $M B$ is miss bias, $F B$ is false bias and $T B$ is total bias.

\section{Result}

The result of descriptive statistics applying mean error $(M E)$ to validate 4 satellite-based rainfall for 4 intensity classification in MAS are presented in Fig. 2 to Fig. 5. The boxplots made for no rain detection for different seasons shows in Figure 2. All 4 satellite-based rainfall generally overestimates no rain events in dry and wet periods especially on driest months (Jul-Sep) and wettest months (Jan-March). CM is mostly only slightly overestimates no rain, while CHR highly overestimates no rain compared to others. TR and IMR have comparable performance in detecting no rain. The difference value of ME between those two can be $0 \mathrm{~mm} \cdot \mathrm{day}^{-1}$ and mostly below $1.0 \mathrm{~mm} \cdot \mathrm{day}^{-1}$.

The boxplot of $M E$ of 4 satellite-based rainfall against 5 rain gauges to detect light rain is presented on Fig. 3 for 4 season separately. The performance of 4 satellite-based rainfall is inconsistent to detect light rain. All 4 satellite-based rainfall can be overestimates and underestimates to detect light rain from gauge observation. The performance of all satellite-based rainfall is generally similar which is no one is superior to one another for all seasons. But, it can be noted that CHR often has lowest underestimation and overestimation on driest months (Jul-Sep) compared to CM, IMR, and TR. Both IMR and TR performance is mostly comparable compared to both $\mathrm{CM}$ and $\mathrm{CHR}$.

The $M E$ boxplot for 4 satellite-based rainfall against 5 rain gauges to detect moderate rain is presented on Fig. 4 for 4 season division separately. The satellite products underestimates moderate rain from rain gauges because rainfall amount from satellite products is lower compared to gauges rainfall amount. CHR mostly has larger discrepancy compared to rain gauges on wet periods on Jan-March and Oct-Dec, while TR has lower discrepancy on Jan-March and IMR on Oct-Dec. CHR consistently performs underestimation on moderate rain on wet and wettest months. CHR has the largest underestimation of moderate rain, while TR is the lowest. 
The boxplot made for daily $M E$ of 4 satellite-based rainfall against 5 rain gauges to detect heavy to extreme rain is presented in Fig. 5. CHR is the most underestimate rainfall on wettest months of JanMarch and on driest months of Jul-Sep, while CM is mostly on Apr-Jun. IMR and TR mostly have comparable performance.

The daily RMSE of 4 satellite-based rainfall against 5 rain gauges to detect no rain shows on Table 3 . From this table, it describes that CHR has superior performance compared to 3 other satellite products. It mostly has the lowest RMSE in almost all 4 season from January to December. TR is the worst performance to detect no rain on wettest months (Jan-March), while CM on dry (Apr-Jun) and driest months (Jul-Sep). Both of them mostly have the largest value of RMSE. Only very few occasion on the driest months (Jul-Sep), CM has lowest discrepancy with rain gauges compared to CHR.

The performance of CHR shows the lowest value of RMSE to detect light rain (Table 4) on wettest months (Jan-March), dry months (Apr-Jun), driest months (Jul-Sep), and wet months (Oct-Dec). The degree of discrepancy of $\mathrm{CHR}$ with rain gauge observation is much lower compared to other satellite-based rainfall. The value of $R M S E$ of $\mathrm{CHR}$ is very lower compared to 3 satellite products especially with $\mathrm{CM}$ on driest months. CM has largest RMSE on dry and driest months of April to September. CM and TR has a good performance compared to IMR on Oct-Dec. CM and TR have larger value of RMSE on wettest months.

The RMSE value of CHR is mostly the lowest to detect moderate rain on Jan-March (Table 5). The most largest values of RMSE of CM occurs on Apr-Jun. CM is more frequent to have large RMSE value compared to others on driest months of Jul-Sep. The value of CHR RMSE is the lowest on wet months of Oct-Dec, while the largest is CM. It seem CHR is superior to detect moderate rain on wet and wettest months. IMR and TR has comparable performance, the frequency of superiority performance to detect moderate rain for one another is similar. IMR and TR have better performance on dry periods which are on driest months or on dry months.

The performance of satellite-based rainfall is mostly comparable to detect heavy to extreme rain (Table 6). Mostly, IMR has low RMSE values. CM mostly has better performance on driest months on July to September. CHR is often to have large RMSE values, followed by $\mathrm{CM}$. It seem most of satellite products has difficulty to estimate heavy to extreme rain because there is no clear indication which satellite product inferior to one another in each season division.

The performance of satellite products in detecting no rain $\left(0 \mathrm{~mm} \cdot \mathrm{day}^{-1}\right)$ is assessed from the frequencies of correct negatives $(C M)$ and false alarm $(F A)$ as in Fig. 6. CM is the best performance to detect no rain on wettest months (Jan-March), followed by TR and CHR. Mostly more than $90 \%$ of no rain events can be detected by CM. IMR is the worst to detect no rain in wettest months. The frequency of $C N$ for IMR is the lowest which also occurs on the wet months of October to December. CM is occasionally to have a good performance to detect no rain on dry and driest months from April to September, followed by TR. IMR is more often to have difficulty to detect no rain on April to September compared to CHR. The satellite 
products is more superior to detect no rain on wet periods (wet and wettest months) than on dry periods (dry and driest months).

IMR mostly has the largest hits $(H)$ frequencies to detect light rain on both wet and dry periods, followed by CHR and TR (Fig. 7). More than $88 \%$ of light rain events can be detected by IMR on wettest months, while CHR more than $81 \%$. TR occasionally has a good performance compared to CHR on dry or driest months so that TR sometime has larger $H$ and lower $M$ compared to $\mathrm{CHR}$ in these dry periods. $\mathrm{CM}$ has the lowest frequency of $H$ for light rain. As a result, $C M$ has the largest number of $M$. The frequency of $M$ for $\mathrm{CM}$ is lower on dry and driest months compared to wet and wettest months especially on driest months. More than $50 \%$ of light rain can be detected by $\mathrm{CM}$ on driest months of July to September.

The spider chart of $H$ and $M$ frequencies in detecting moderate rain for 4 satellite-based rainfall against 5 rain gauges from 1 January 2008 to 31 December 2012 shows in Fig. 8 for each season separately. The performance of 4 satellite products to detect moderate rain almost similar with light rain. IMR is more often to have the largest $H$ frequency, followed by $\mathrm{CHR}$ and TR. More than $90 \%$ of light rain events can be detected by IMR on wettest months, while CHR more than $84 \%$. But occasionally the performance of IMR, $\mathrm{CHR}$, or TR is comparable on dry or driest months. The frequency of $H$ for $\mathrm{CM}$ is mostly the lowest in all season.

$\mathrm{CM}$ is not a good performance to detect heavy to extreme rain (Fig. 9). It has the lowest frequency of $H$ and largest frequency of $M$. IMR has the largest frequency number of $H$ to detect heavy to extreme rain, followed by CHR. TR is better performance than CM. It has lower frequency of $M$ than $\mathrm{CM}$.

The spatial maps of $R s$ or $T B$ in detecting no rain $\left(0 \mathrm{~mm} \cdot\right.$ day $\left.^{-1}\right)$ for 4 satellite-based rainfall against 5 rain gauges from 1 January 2008 to 31 December 2012 is shown in Fig. 10. CM has the lowest Rs or TB on the wettest months of January to March, while CHR is the largest. IMR has the better performance compared to TR. CM mostly has the lowest $T B$ on driest and wet months. It means $\mathrm{CM}$ has the largest accuracy to detect no rain. IMR and CHR has the larger $T B$ compared to TR on dry months of April to June. Station located near mountain range or mountain rise, i.e. Tanjungtirto and Kemput, has larger $T B$ values compared to other stations. It is because satellite products falsely detect rainy events leading to large value of $T B$. It is mostly only $10-20 \%$ of no rain can be detected by satellite products on wet periods, exception for $\mathrm{CM}$. It is probably the wind flow from south to north that make satellite products falsely detect rainy events. The air mass flows from the sea sweep away to the direction of mountain peak of volcano to create orographic precipitation. Particularly, the wind speed is mostly more slowly in wet periods. The wind speed is approximately $80 \mathrm{~km} /$ day ( 1.8 knots/day) near mountain rise in wet periods, while in driest months of July to September $100 \mathrm{~km} /$ day $(2.25 \mathrm{knots} /$ day $)$.

The spatial maps radar chart of bias decomposition component for $M B$ and $A H B$ in detecting light rain for 4 satellite-based rainfall against 5 rain gauges from 1 January 2008 to 31 December 2012 is shown in Fig. 10. IMR generally has lowest $M B$ and $C M$ the largest $M B$ in detecting light rain on wet and dry periods. The $M B$ values of $C M$ is much larger compared with $M B$ values of $C H R$ in wet periods and TR in 
dry periods. CHR has lower $M B$ compared to TR on wet and wettest periods. It is an opposite condition on dry and driest months, TR has lower $M B$ compared to $C H R$. All satellite products has large values of $A H B$ on Jan-March (wettest months) and Oct-Dec (wet months). All of them has large values of $A H B$ near the mountain range. $A H B$ of $\mathrm{CHR}$ has the lowest values on wet and wettest months indicating this satellitebased rainfall a good performance to detect rain amount on wet periods. IMR mostly has the largest values of $A H B$ on all season on wet and dry periods. IMR is not a good performance to detect rain amount of light rain.

IMR and CHR mostly has comparable performance to detect moderate rain compared to $\mathrm{CM}$ and TR on wettest and dry months (Fig. 10). Both of them has low values of $M B$. CM is poor performance than TR. IMR has a good performance on wet months of October to December, followed by CHR and TR. CM has the largest $M B$ values in these months. IMR has low values of $M B$ because it has the lowest $M$ frequency to detect rainfall intensity more than $0 \mathrm{~mm} \cdot$ day $^{-1}$. But IMR has the largest value of $A H B$ indicating this satellite product is not a good performance to detect rain amount. $\mathrm{CM}$ generally has the lowest $A H B$ in all periods, followed by CHR. For example in Bronggang Station, the accuracy of IMR to detect rain amount is $1 / 3$ of $C M$, while $1 / 2$ of CHR. However, all satellite-based rainfall has largest values of $A H B$ in Bronggang station near the top of Merapi Volcano. It is probably the orographic events surrounding this mountain that make satellite products have difficulty to estimate rain amount.

$\mathrm{CHR}$ is not a good performance to estimate heavy to extreme rain (Fig 10). It mostly has the largest $A H B$ values. The second place that have large $A H B$ values is IMR or TR. Usually, IMR is a good performance compared to TR on driest months of Jul-Sep, while TR on dry months of Apr-Jun. On high altitude rain gauges stations, such as Bronggang, Kemput and Tanjungtirto, CHR has better accuracy to detect heavy to extreme rain on wet periods compared to IMR and TR. This satellite product has lower $A H B$ values than IMR and TR in wet periods. CM has the largest accuracy to detect rain amount of heavy to extreme rain. The value of $A H B$ for $C M$ is the lowest. In contrast with $A H B$ values, $M B$ of $C M$ is the largest. IMR is mostly has the lowest $M B$ values and $C H R$ is better accuracy than TR to estimate heavy to extreme rain. $C M$ has the largest frequency of $M$ so that the value of $M B$ will be large although $C M$ is a good accuracy to estimate rain amount. The second place to have a good accuracy to estimate rain amount is $\mathrm{CHR}$.

\section{Discussion And Conclusion}

A sparse density of rain gauge is a challenging task to estimate strong spatial-temporal variability of precipitation in a tropics (Rahmawati and Lubczynski 2018). Accurate and reliable satellite-based rainfall is necessary to be merged with gauge-based rainfall to catch diurnal cycle of precipitation in tropics (Rahmawati 2020). Before satellite-based rainfall is merged to rain gauge observation, it is important to evaluate the performance of satellite-based rainfall. One of the ways to evaluate the performance of satellite-based rainfall is by the direct comparison of satellite-based rainfall against gauge observations or point-to-point comparison as applied in MAS (Bai and Liu 2018; Belay et al. 2019; Chen et al. 2016; Luo et al. 2019). There are several consideration to evaluate the performance of 
satellite-based rainfall: i) the detail knowledge of rainfall characteristics, ii) algorithm of satellite-based rainfall, and iii) resolution of satellite-based rainfall.

The detail knowledge of rainfall characteristics, i.e. rainfall intensity, is essential to evaluate remotely sensed rainfall estimates (Mandapaka and Qin 2013). It is important to provide nature and characteristics of rainfall and better prediction of hydrologic response in watersheds and urban areas (Chen et al. 2016) since rainfall exhibit different mean value and variability at daily time series (Choubin et al. 2019). The error estimation of satellite-based rainfall in frequencies and intensities of daily precipitation influences the simulation result of surface water, sub-surface water, evapotranspiration and different amount and proportion of simulated water balance components (Luo et al. 2019). The daily satellite-based rainfall (CM, IMR, TR, and CHR) mostly overestimates rainfall intensity $\leq 20 \mathrm{~mm} \cdot \mathrm{day}^{-1}$. It is because satellite estimation from infrared and microwave lead an overestimation of rainfall amount due to ignorance of the surface altitude in the algorithm. Evaporation of rainfall below the cloud base in complex terrain is not counted because rainfall retrieval is from brightness temperature at cloud top (Scheel et al. 2011). The satellite-based rainfall overestimates rainfall in MAS because of the possibility of cloud microphysical, rain processes and moisture distribution in the environment (McCollum et al. 2000). The daily satellite-based rainfall underestimates rainfall intensity $\geq$ $50 \mathrm{~mm} \cdot$ day $^{-1}$. The range of underestimation is much higher especially for extreme rainfall ( $\geq 150$ $\mathrm{mm} \cdot$ day $\left.^{-1}\right)$. It is probably satellite-based rainfall has a tendency to underestimates convective rain amounts (Bell and Kundu 2003). In convective system, infrared estimates rainfall from cirrus cloud that do not produce any precipitation (Scheel et al. 2011).

A multitude of technique is developed and available for the estimation and retrieval of rainfall for satellite sensors (Kidd and McGregor 2007). The algorithm of satellite-based rainfall is mainly based on microwave and infrared sensors together with ground-based data (radar or rain gauge) or multiple sensors (Freitas et al. 2020; Kidd and Levizzani 2011; Tapiador et al. 2012). The nature of error can change with the update of retrieval algorithm and the change of data source leading to different performance of satellite-based rainfall for different region, season and precipitation type, i.e., rainfall intensity (Ebert et al. 2007; Guo et al. 2015). CHIRPS (CHR) is best performed compared to others satellite-based rainfall. This satellite product mostly shows lowest RMSE especially in rainfall intensity < $50 \mathrm{~mm} \cdot$ day $^{-1}$. CHR is best performance because it apparently the infrared precipitation determine to effectively represent some of the systematic climate effects of complex terrain (Funk et al. 2014). TR and IMR have almost similar performances. The value of rainfall amount occasionally is similar or comparable. It is because the new satellite sensors and algorithmic from TR to IMR leads to mixed performance regarding various rainfall intensities (He et al. 2017).

The different performances observed for different rainfall intensities could be attributed to the intrinsic features of satellite-based rainfall, i.e. TR and IMR, produced by algorithmic and sensors discrepancy (He et al. 2017). CM is best performance to detect no rain. CM has the most frequent hits $(H)$ for no rain that is why this satellite product has the lowest overestimation toward rain gauge data. Mostly, all satellite- 
based rainfall performs worse in estimating rainfall intensity $\geq 50 \mathrm{~mm} \cdot$ day $^{-1}$. CHR also performs worse in detecting heavy to extreme rain. It can be seen from the larger values of RMSE compared to others. It is in agreement with Funk et al. (2015). IMR generally has a good performance compared with TR. IMR advanced satellite sensors leading the IMR detects the occurrences of light-rain and extreme heavy-rain ranks better than TR does, although IMR tends to produce significant overestimation of the amounts of extreme rain events (He et al. 2017).

The performance of satellite products is different for dry and wet periods. The performance of satellitebased rainfall is good in wet periods (wet and wettest months) and worse in dry periods (dry and driest months) such as CHR. It is probably the rain-rate variability especially during dry seasons is likely to be much stronger and tend to have strong diurnal modulations for satellite algorithm (Bell and Kundu 2003). It is also because limited ability to differentiate drizzle or frozen rainfall during the later period (Wu et al. 2019). CM and TR mostly has a good performance in dry periods. It is because the inability of the technique to retrieve precipitation during wet season, either through a greater low-intensities precipitation or because of cold surface background affecting PMW retrievals (Kidd et al. 2012).

Satellite-based rainfall is able to detect spatial and temporal variability of rainfall at finer resolution (Chen et al. 2016; Rahmawati 2020). The resolution and time step of spatial satellite-based rainfall influence the accuracy and outcome of precipitation-based analysis (Gupta et al. 2020), i.e. the lowest RMSE values of CHR. However, it is not fully in agreement based on this research in MAS. The advanced algorithm of satellite-based rainfall also give an effect on the accuracy to estimate rainfall, i.e. lowest $M B$ values of IMR. CHR mostly be in the second place to have low values of $M B$. The traditional algorithm of satellitebased rainfall that also does not use rain gauge data to estimate rainfall influences accuracy of rainfall estimates, i.e. the largest $H$ frequency of $\mathrm{CM}$ for no rain detection and lowest values of $A H B$ of $\mathrm{CM}$. It is because rain gauge data that is used for bias correction or bias adjustment for satellite rainfall estimates does not represent study area.

Eastern and western MAS is generally treated as climatically separate units that influences modulation precipitation in the groundwater basin of MAS. It is perhaps one of the reason satellite-based rainfall is not a good performance to detect certain rainfall amount in MAS. All 4 satellite-based rainfall also poor in estimating moderate to extreme rain, although CHR mostly show better performance compared to others. All satellite products mostly has large values of $A H B$ along mountain range. The rain may not fall with equal possibilities at different time of the day at different points such as near coast and near mountain range (Bell and Kundu 2003). PMW sounding instruments are relatively insensitive to surface emissions and therefore are essentially immune to cold background issues (Kidd et al. 2012) such as along mountain range or hills. Therefore, satellite-based rainfall has lower accuracy to detect rainy events along mountain range or hills in MAS. It shows from large values of $M B$ and $A H B$ along hills and mountain range.

It is recommended to validate 4 satellite-based rainfall based on streamflow simulation in hydrological modeling framework before it applies for water resources application and related studies. It is because 
point-to-point comparison or simple interpolation can create bias (Chen et al. 2016) and the error of satellite-based rainfall can show in time series streamflow simulation (Bai and Liu 2018). The satellite product can be corrected with rain gauge data and/or merged with other satellite products to obtain advantages of each satellite product. It is better not to merge IMR and TR because both of them often have comparable performance and IMR is an improvement algorithm of TR. It is also possible to use certain satellite product that good performance to detect no rain so that it is good for drought application such as CM in dry periods and CHR in wet periods or combine both of them. It is because CM has a good performance to detect no rain and mostly has lowest values of $A H B$ from light to extreme rain, while CHR has a good performance to estimate light to moderate rain. CHR mostly has the lowest RMSE values, low values of $A H B$ (after CM), low values of $M B$ (after IMR). CHR mostly has better performance compared to others.

\section{Declarations}

\section{Conflict of Interest}

The authors declare that they have no known competing financial interests or personal relationships that could have appeared to influence the work reported in this paper.

\section{Funding Statement}

This research did not receive any specific grant from funding agencies in the public, commercial, or notfor-profit sectors.

\section{Author Affiliation}

Department of Water Resources, Faculty of Geo-Information Science and Earth Observation (ITC), University of Twente, Enschede, The Netherlands

Novi Rahmawati

Serayu Opak River Basin Organization (BBWS Serayu Opak), Ministry of Public Works and Housing, Yogyakarta, Indonesia

Kisworo Rahayu

Bureau of Geophysics, Meteorology and Climatology (BMKG), Makassar, Sulawesi, Indonesia

Sukma Tri Yuliasari

Corresponding Author

Correspondence to Novi Rahmawati (novira.wati@gmail.com)

\section{Author's Contribution}


Novi Rahmawati is Conceptualization, Methodology, Software, Validation, Formal Analysis, Investigation including data collection, data curation including software code, visualization, writing-original draft. Kisworo Rahayu is Investigation-data collection and writing-reviewing and editing. Sukma Tri Yuliasari is writing-reviewing and editing

\section{Availability of Data and Material}

All data published in this article are available upon request except the raw data of daily rainfall and wind speed from gauge stations. The rain gauge and wind speed data have to be requested from Serayu Opak River Basin Organization (BBWS Serayu Opak), Ministry of Public Works and Housing in Yogyakarta Special Province, Indonesia (http://sda.pu.go.id/balai/bbwsserayuopak/).

\section{Code Availability}

Code is available from the author upon request.

\section{Consent to Participate}

The manuscript has been read and approved by all named authors and that there are no other persons who satisfied the criteria for authorship but are not listed. The order of authors listed in the manuscript has been approved by all of the authors.

\section{Consent for Publication}

The authors transfer to Springer the non-exclusive publication rights. The transfer of publication rights covers the non-exclusive rights to reproduce and distribute the article including re-prints, translations, photographic reproductions, electric forms (online, offline), or any other reproductions of similar nature.

\section{Additional Information}

Publisher's note

Springer Nature remains neutral with regard to jurisdictional claims in published maps and institutional affiliations.

\section{Acknowledgement}

The authors would like to thank to Department of Water Resources, Faculty of Geo-Information Science and Earth Observation (ITC), University of Twente, The Netherlands for software licenses and library access. The authors thanks to Serayu Opak River Basin Organization (BBWS Serayu Opak), Ministry of Public Works and Housing in Yogyakarta Special Province, Indonesia to measure and provide the data of daily rainfall from rain gauge stations and wind speed data from climatology stations. The authors thanks to Climate Prediction Center, NOAA/ National Weather Service to provide the CMORPH data that can be accessed by ITC ILWIS Toolbox. The author thank to NASA/Goddard Space Flight Center's and 
PPS to develop, compute and provide the dataset of TRMM and GPM-IMERG and it is archived at the NASA GES DISC. The authors thank to Climate Hazard Center, University of California to provide the data of CHIRPS. The authors would like to thank to anonymous reviewers for the help to improve this manuscript.

\section{References}

Aksu, H., \& Akgül, M.A. (2020). Performance evaluation of CHIRPS satellite precipitation estimates over Turkey. Theoretical and Applied Climatology, 142, 71-84

Andersen, J., Refsgaard, J.C., \& Jensen, K.H. (2001). Distributed hydrological modelling of the Senegal River Basin - model construction and validation. Journal of Hydrology, 247, 200-214

Bai, P., \& Liu, X. (2018). Evaluation of Five Satellite-Based Precipitation Products in Two Gauge-Scarce Basins on the Tibetan Plateau. Remote Sensing, 10, 1316

Becker, A., \& Braun, P. (1999). Disaggregation, aggregation and spatial scaling in hydrological modelling. Journal of Hydrology, 217, 239-252

Belay, A.S., Fenta, A.A., Yenehun, A., Nigate, F., Tilahun, S.A., Moges, M.M., Dessie, M., Adgo, E., Nyssen, J., Chen, M., Griensven, A.V., \& Walraevens, K. (2019). Evaluation and Application of Multi-Source Satellite Rainfall Product CHIRPS to Assess Spatio-Temporal Rainfall Variability on Data-Sparse Western Margins of Ethiopian Highlands. Remote Sensing, 11, 2688

Bell, T.L., \& Kundu, P.K. (2003). Comparing satellite rainfall estimates with rain gauge data: Optimal strategies suggested by a spectral model. Journal of Geophysical Research: Atmospheres, 108

BMKG (2010). Kondisi Cuaca Ekstrem dan Iklim Tahun 2010-2011. In. Jakarta: BMKG (Indonesia Agency for Meteorology, Climatology, and Geophysics

Brauer, C.C., Overeem, A., Leijnse, H., \& Uijlenhoet, R. (2016). The effect of differences between rainfall measurement techniques on groundwater and discharge simulations in a lowland catchment. Hydrological Processes, 30, 3885-3900

Chen, H., Yu, R., \& Shen, Y. (2016). A new method to compare hourly rainfall between station observations and satellite products over central-eastern China. Journal of Meteorological Research, 30, 737-757

Choubin, B., Khalighi-Sigaroodi, S., Mishra, A., Goodarzi, M., Shamshirband, S., Ghaljaee, E., \& Zhang, F. (2019). A novel bias correction framework of TMPA 3B42 daily precipitation data using similarity matrix/homogeneous conditions. Science of The Total Environment, 694, 133680

Derin, Y., Anagnostou, E., Berne, A., Borga, M., Boudevillain, B., Buytaert, W., Chang, C.-H., Delrieu, G., Hong, Y., Hsu, Y.C., Lavado-Casimiro, W., Manz, B., Moges, S., Nikolopoulos, E.I., Sahlu, D., Salerno, F., Rodríguez- 
Sánchez, J.-P., Vergara, H.J., \& Yilmaz, K.K. (2016). Multiregional Satellite Precipitation Products Evaluation over Complex Terrain. Journal of Hydrometeorology, 17, 1817-1836

Ebert, E.E., Janowiak, J.E., \& Kidd, C. (2007). Comparison of Near-Real-Time Precipitation Estimates from Satellite Observations and Numerical Models. Bulletin of the American Meteorological Society, 88, 47-64

Freitas, E.d.S., Coelho, V.H.R., Xuan, Y., Melo, D.d.C.D., Gadelha, A.N., Santos, E.A., Galvão, C.d.O., Ramos Filho, G.M., Barbosa, L.R., Huffman, G.J., Petersen, W.A., \& Almeida, C.d.N. (2020). The performance of the IMERG satellite-based product in identifying sub-daily rainfall events and their properties. Journal of Hydrology, 589, 125128

Funk, C., Peterson, P., Landsfeld, M., Pedreros, D., Verdin, J., Shukla, S., Husak, G., Rowland, J., Harrison, L., Hoell, A., \& Michaelsen, J. (2015). The climate hazards infrared precipitation with stations-a new environmental record for monitoring extremes. Scientific Data, 2, 150066

Funk, C.C., Peterson, P.J., Landsfeld, M.F., Pedreros, D.H., Verdin, J.P., Rowland, J.D., Romero, B.E., Husak, G.J., Michaelsen, J.C., \& Verdin, A.P. (2014). A quasi-global precipitation time series for drought monitoring. In, Data Series (p. 12). Reston, VA

Guo, H., Chen, S., Bao, A., Hu, J., Gebregiorgis, A.S., Xue, X., \& Zhang, X. (2015). Inter-Comparison of HighResolution Satellite Precipitation Products over Central Asia. Remote Sensing, 7, 7181-7211

Gupta, V., Jain, M.K., Singh, P.K., \& Singh, V. (2020). An assessment of global satellite-based precipitation datasets in capturing precipitation extremes: A comparison with observed precipitation dataset in India. International Journal of Climatology, 40, 3667-3688

Habib, E., Haile, A.T., Sazib, N., Zhang, Y., \& Rientjes, T. (2014). Effect of Bias Correction of SatelliteRainfall Estimates on Runoff Simulations at the Source of the Upper Blue Nile. Remote Sensing, 6, 66886708

He, Z., Yang, L., Tian, F., Ni, G., Hou, A., \& Lu, H. (2017). Intercomparisons of Rainfall Estimates from TRMM and GPM Multisatellite Products over the Upper Mekong River Basin. Journal of Hydrometeorology, 18, 413-430

Hou, A.Y., Kakar, R.K., Neeck, S., Azarbarzin, A.A., Kummerow, C.D., Kojima, M., Oki, R., Nakamura, K., \& Iguchi, T. (2014). The Global Precipitation Measurement Mission. Bulletin of the American Meteorological Society, $95,701-722$

Huffman, G.J., E.F., S., D.T., B., E.J., N., \& Jackson, T. (2019). GPM IMERG Final Precipitation L3 1 day 0.1 degree x 0.1 degree V06. In A. Savtchenko, Greenbelt, MD, \& G.E.S.D.a.I.S.C.G. DISC) (Eds.)

Janowiak, J.E., Kousky, V.E., \& Joyce, R.J. (2005). Diurnal cycle of precipitation determined from the CMORPH high spatial and temporal resolution global precipitation analyses. Journal of Geophysical Research: Atmospheres, 110 
Joyce, R., Janowiak, J., Arkin, P., \& Xie, P. (2004). CMORPH: A Method That Produces Global Precipitation Estimates From Passive Microwave and Infrared Data at High Spatial and Temporal Resolution. Journal of Hydrometeorology - J HYDROMETEOROL, 5

Joyce, R.J., Xie, P., Yarosh, Y., Janowiak, J.E., \& Arkin, P.A. (2010). CMORPH: A “Morphing” Approach for High Resolution Precipitation Product Generation. In M. Gebremichael, \& F. Hossain (Eds.), Satellite Rainfall Applications for Surface Hydrology (pp. 23-37). Dordrecht: Springer Netherlands

Kidd, C., Bauer, P., Turk, J., Huffman, G.J., Joyce, R., Hsu, K.-L., \& Braithwaite, D. (2012). Intercomparison of High-Resolution Precipitation Products over Northwest Europe. Journal of Hydrometeorology, 13, 67-83

Kidd, C., \& Levizzani, V. (2011). Status of satellite precipitation retrievals. Hydrol. Earth Syst. Sci., 15, 11091116

Kidd, C., \& McGregor, G. (2007). Observation and characterisation of rainfall over Hawaii and surrounding region from the Tropical Rainfall Measuring Mission. International Journal of Climatology, 27, 541-553

Liu, J., Shangguan, D., Liu, S., Ding, Y., Wang, S., \& Wang, X. (2019). Evaluation and comparison of CHIRPS and MSWEP daily-precipitation products in the Qinghai-Tibet Plateau during the period of 19812015. Atmospheric Research, 230, 104634

Luo, X., Wu, W., He, D., Li, Y., \& Ji, X. (2019). Hydrological Simulation Using TRMM and CHIRPS Precipitation Estimates in the Lower Lancang-Mekong River Basin. Chinese Geographical Science, 29, 1325

Ma, Q., Xiong, L., Xia, J., Xiong, B., Yang, H., \& Xu, C.-Y. (2019). A Censored Shifted Mixture Distribution Mapping Method to Correct the Bias of Daily IMERG Satellite Precipitation Estimates. Remote Sensing, 11,1345

Maathuis, B., Mannaerts, C., Schouwenburg, M., Retsios, B., Lemmens, R., \& Nkepu, M.R. (2014). In Situ and Online Data Toolbox Installation, Configuration and User Guide. In. Enschede: Faculty of GeoInformation Science and Earth Observation, University of Twente

Mandapaka, P.V., \& Qin, X. (2013). Analysis and Characterization of Probability Distribution and SmallScale Spatial Variability of Rainfall in Singapore Using a Dense Gauge Network. Journal of Applied Meteorology and Climatology, 52, 2781-2796

McCollum, J.R., Gruber, A., \& Ba, M.B. (2000). Discrepancy between Gauges and Satellite Estimates of Rainfall in Equatorial Africa. Journal of Applied Meteorology, 39, 666-679

Michaelides, S., Levizzani, V., Anagnostou, E., Bauer, P., Kasparis, T., \& Lane, J.E. (2009). Precipitation: Measurement, remote sensing, climatology and modeling. Atmospheric Research, 94, 512-533 
O, S., \& Kirstetter, P.-E. (2018). Evaluation of diurnal variation of GPM IMERG-derived summer precipitation over the contiguous US using MRMS data. Quarterly Journal of the Royal Meteorological Society, 144, 270-281

Park, S., Berenguer, M., \& Sempere-Torres, D. (2019). Long-term analysis of gauge-adjusted radar rainfall accumulations at European scale. Journal of Hydrology, 573, 768-777

Pfeifroth, U., Trentmann, J., Fink, A.H., \& Ahrens, B. (2015). Evaluating Satellite-Based Diurnal Cycles of Precipitation in the African Tropics. Journal of Applied Meteorology and Climatology, 55, 23-39

Rahmawati, N. (2020). Space-time variogram for daily rainfall estimates using rain gauges and satellite data in mountainous tropical Island of Bali, Indonesia (Preliminary Study). Journal of Hydrology, 590, 125177

Rahmawati, N., \& Lubczynski, M.W. (2018). Validation of satellite daily rainfall estimates in complex terrain of Bali Island, Indonesia. Theoretical and Applied Climatology, 134, 513-532

Rozante, J.R., Vila, D.A., Barboza Chiquetto, J., Fernandes, A.D.A., \& Souza Alvim, D. (2018). Evaluation of TRMM/GPM Blended Daily Products over Brazil. Remote Sensing, 10, 882

Sacré Regis M., D., Mouhamed, L., Kouakou, K., Adeline, B., Arona, D., Houebagnon Saint. J., C., Koffi Claude A., K., Talnan Jean H., C., Salomon, O., \& Issiaka, S. (2020). Using the CHIRPS Dataset to Investigate Historical Changes in Precipitation Extremes in West Africa. Climate, 8, 84

Scheel, M.L.M., Rohrer, M., Huggel, C., Santos Villar, D., Silvestre, E., \& Huffman, G.J. (2011). Evaluation of TRMM Multi-satellite Precipitation Analysis (TMPA) performance in the Central Andes region and its dependency on spatial and temporal resolution. Hydrol. Earth Syst. Sci., 15, 2649-2663

Skofronick-Jackson, G., Kirschbaum, D., Petersen, W., Huffman, G., Kidd, C., Stocker, E., \& Kakar, R. (2018). The Global Precipitation Measurement (GPM) mission's scientific achievements and societal contributions: reviewing four years of advanced rain and snow observations. Quarterly Journal of the Royal Meteorological Society, 144, 27-48

Sorooshian, S., AghaKouchak, A., Arkin, P., Eylander, J., Foufoula-Georgiou, E., Harmon, R., Hendrickx, J.M.H., Imam, B., Kuligowski, R., Skahill, B., \& Skofronick-Jackson, G. (2011). Advanced Concepts on Remote Sensing of Precipitation at Multiple Scales. Bulletin of the American Meteorological Society, 92, 1353-1357

Stephens, G.L., \& Kummerow, C.D. (2007). The Remote Sensing of Clouds and Precipitation from Space: A Review. Journal of the Atmospheric Sciences, 64, 3742-3765

Tapiador, F.J., Turk, F.J., Petersen, W., Hou, A.Y., García-Ortega, E., Machado, L.A.T., Angelis, C.F., Salio, P., Kidd, C., Huffman, G.J., \& de Castro, M. (2012). Global precipitation measurement: Methods, datasets and applications. Atmospheric Research, 104-105, 70-97 
Wu, W., Li, Y., Luo, X., Zhang, Y., Ji, X., \& Li, X. (2019). Performance evaluation of the CHIRPS precipitation dataset and its utility in drought monitoring over Yunnan Province, China. Geomatics, Natural Hazards and Risk, 10, 2145-2162

Xie, P., Joyce, R., Wu, S., Yoo, S.-H., Yarosh, Y., Sun, F., \& Lin, R. (2017). Reprocessed, Bias-Corrected CMORPH Global High-Resolution Precipitation Estimates from 1998. Journal of Hydrometeorology, 18, 1617-1641

Zhang, X., \& Anagnostou, E.N. (2019). Evaluation of Numerical Weather Model-Based Satellite Precipitation Adjustment in Tropical Mountainous Regions. Journal of Hydrometeorology, 20, 431-445

\section{Tables}

Due to technical limitations the Tables are available as downloads in the Supplementary Files.

\section{Figures}

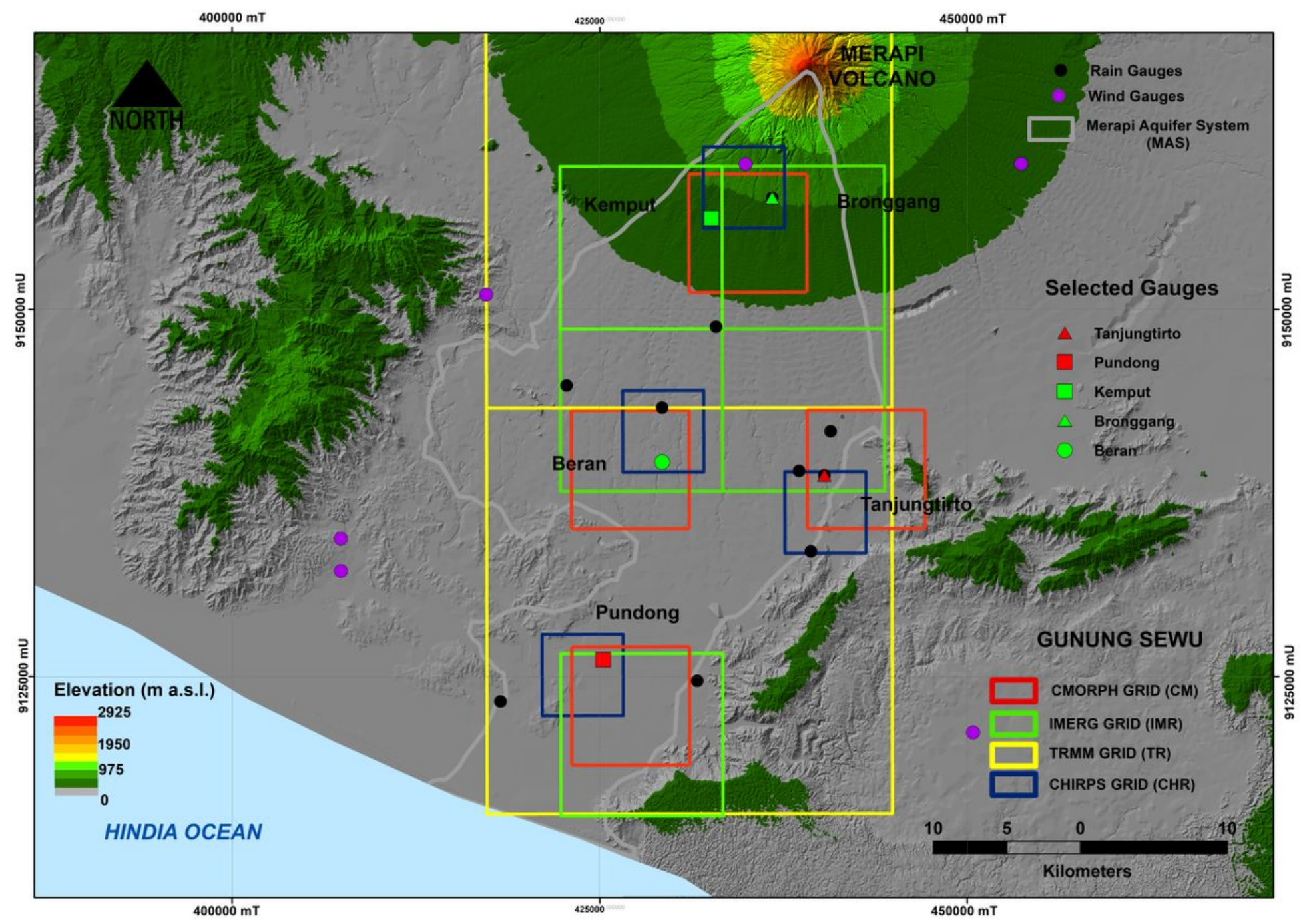

Figure 1 
The boundaries and the location of 13 rain gauges for validation of satellite-based rainfall in Merapi Aquifer System (MAS)

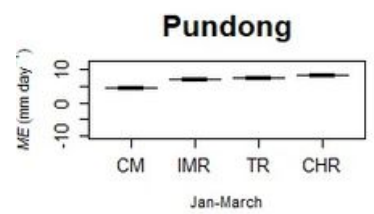

Pundong

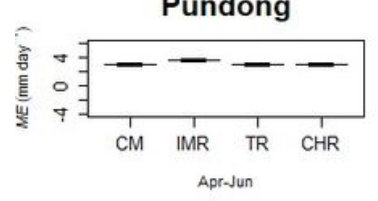

Pundong
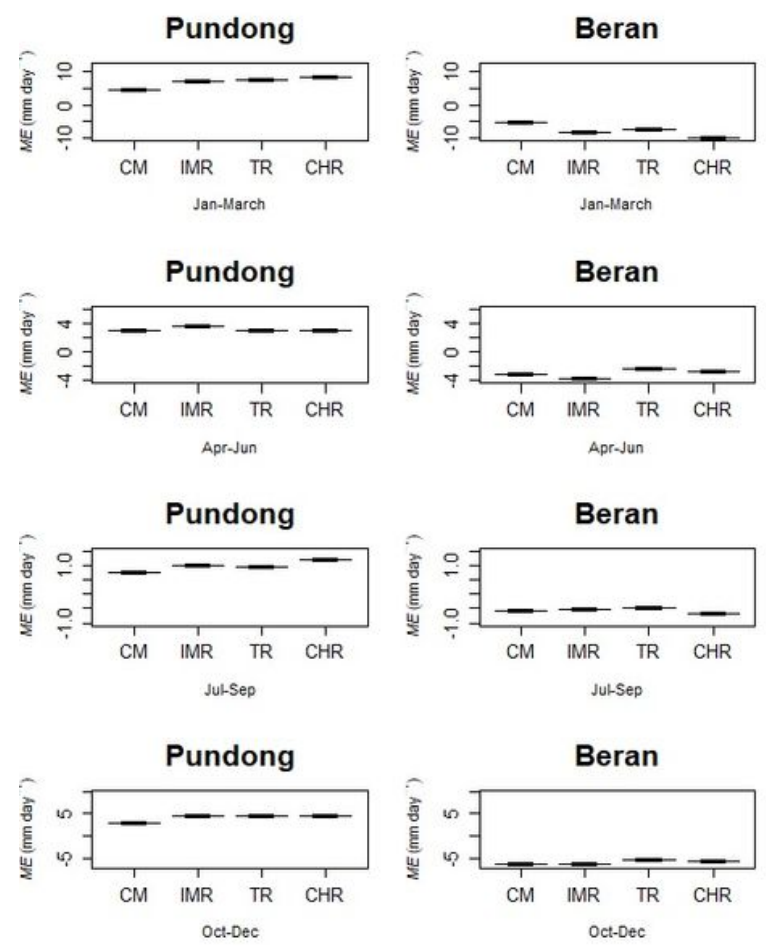

Beran

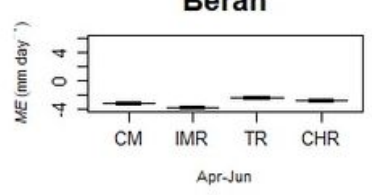

Beran
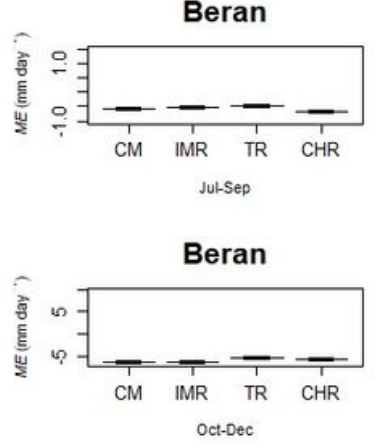

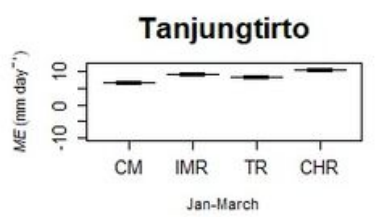

Tanjungtirto
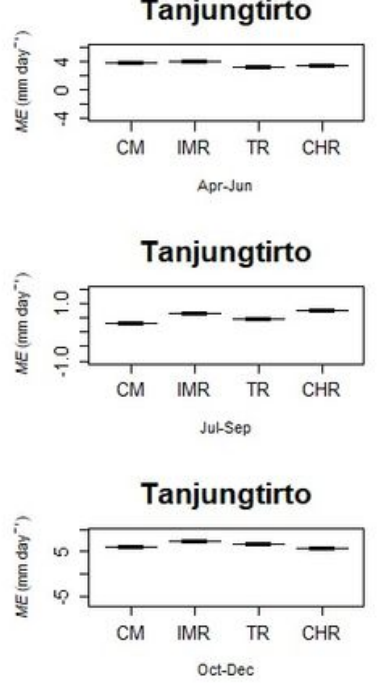
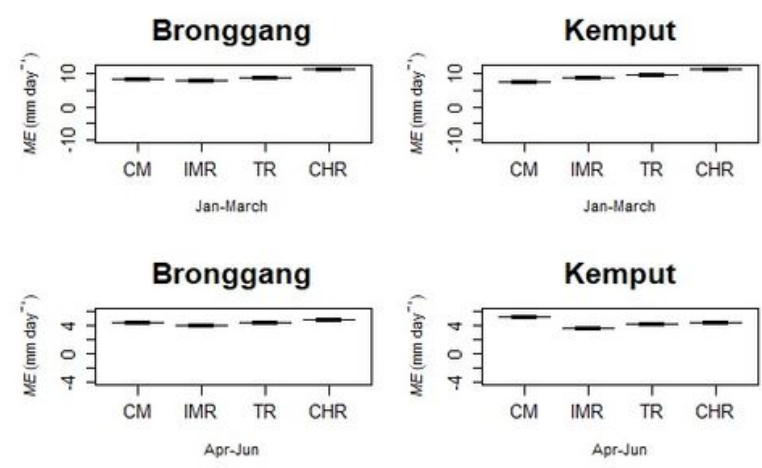

Kemput
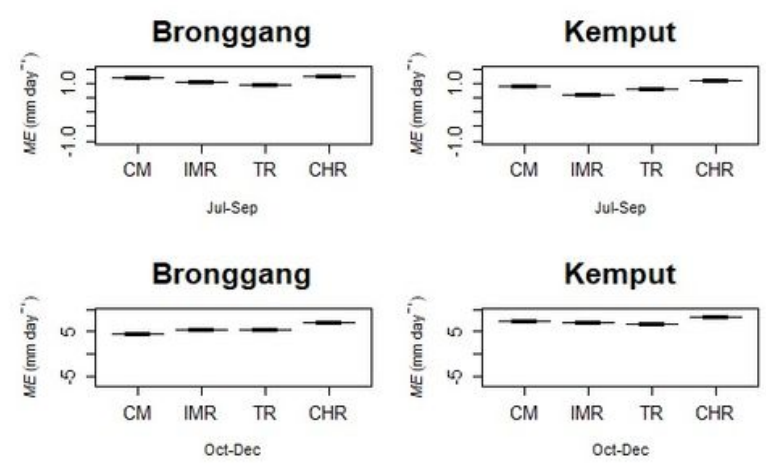

\section{Figure 2}

The boxplot of daily Mean Error (ME) of 4 satellite-based rainfall against 5 selected rain gauges for rainfall intensity 0 mm·day-1 (no rain) from 1 January 2008 to December 2012
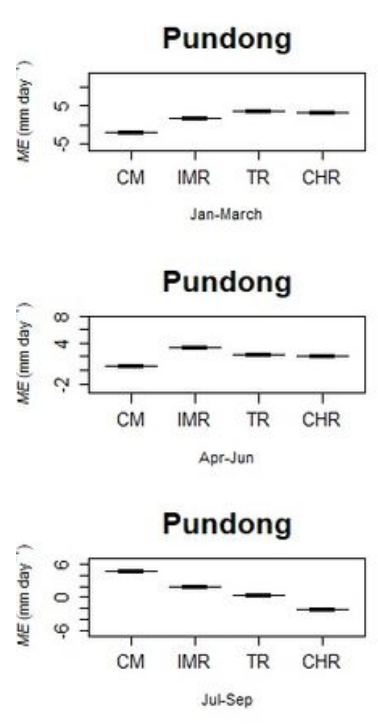

Pundong
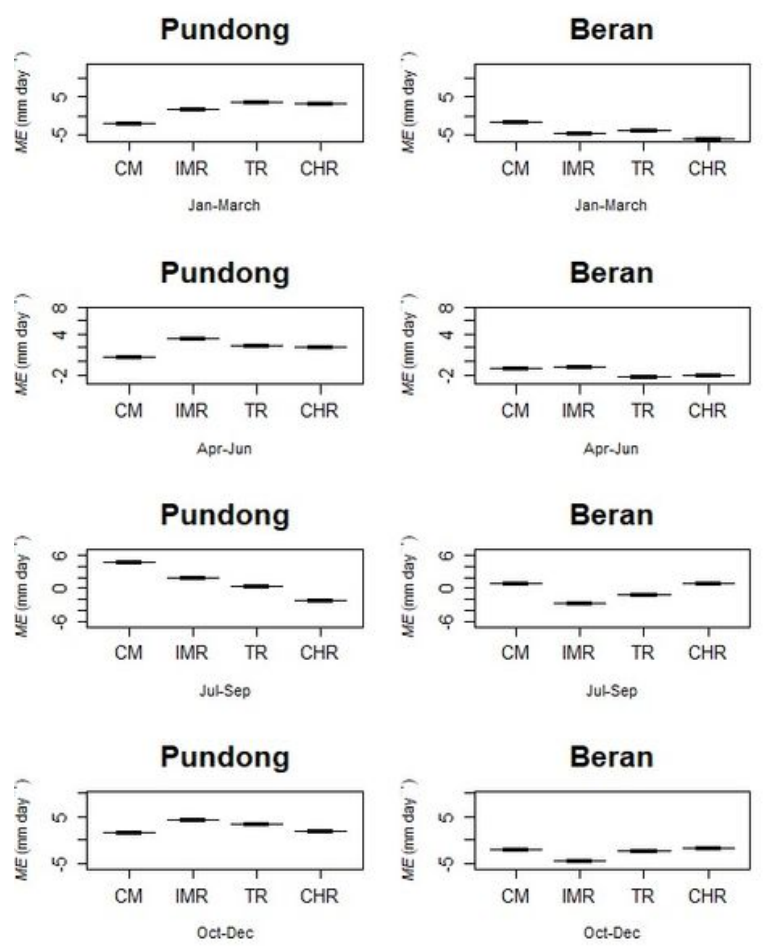

Beran

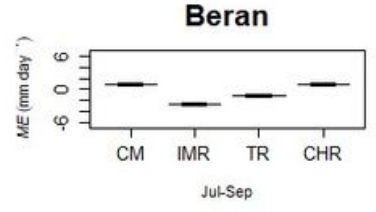

Beran
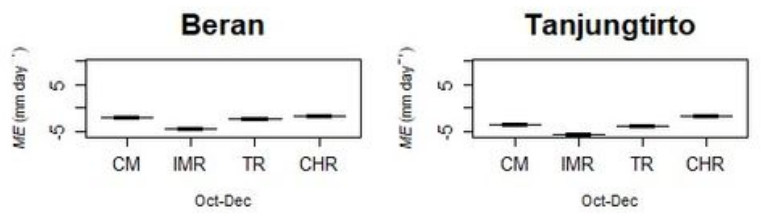

Tanjungtirto
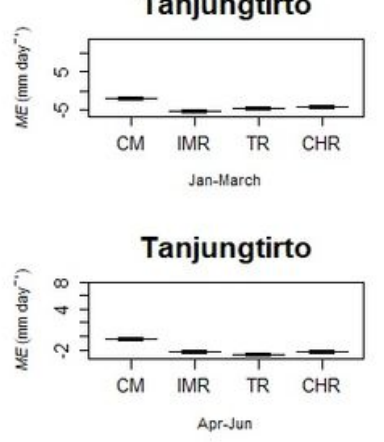

Tanjungtirto

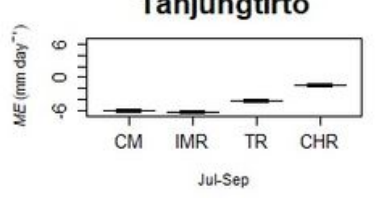

Tanjungtirto

\section{Figure 3}
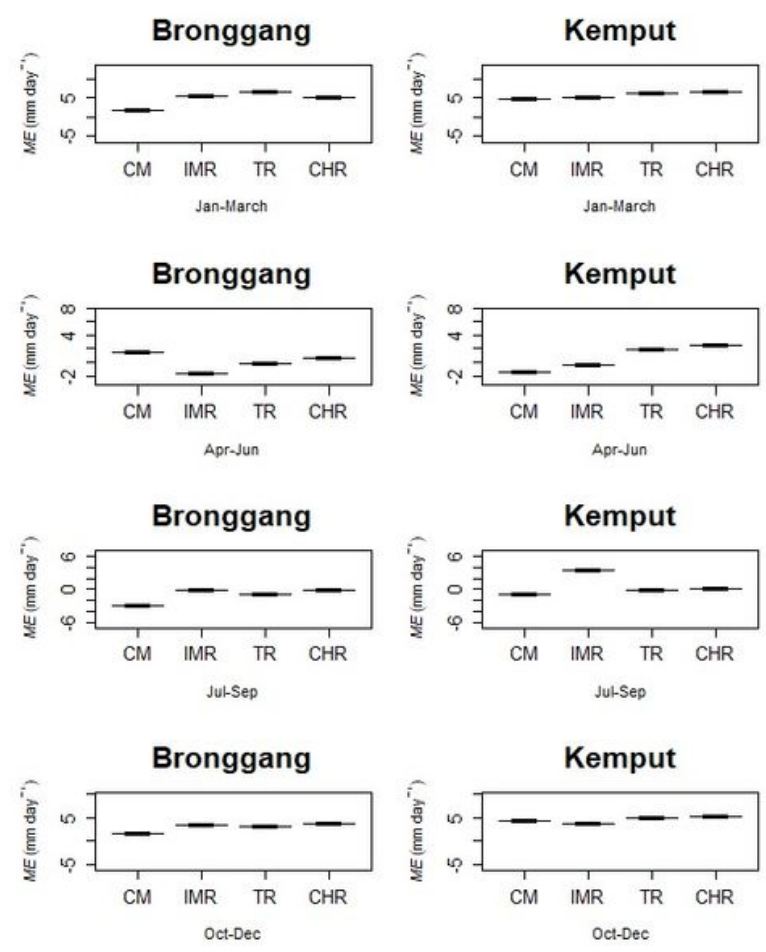
The boxplot of daily Mean Error (ME) of 4 satellite-based rainfall against 5 selected rain gauges for light rain from 1 January 2008 to December 2012

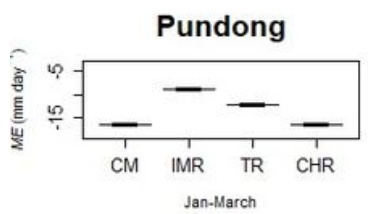

Pundong

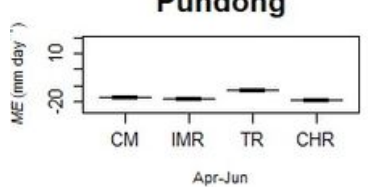

Pundong

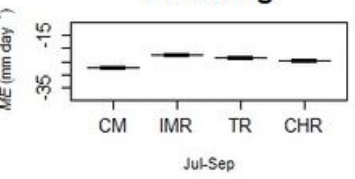

Pundong
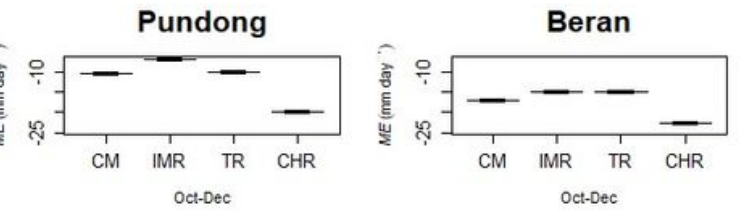

Beran

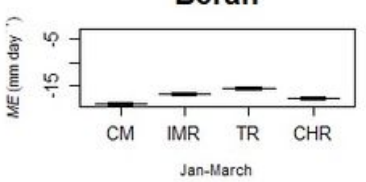

Beran

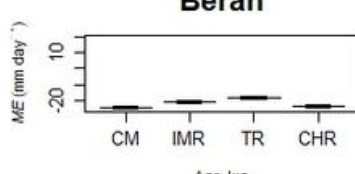

Beran

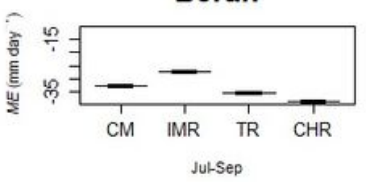

Beran

Figure 4
Tanjungtirto

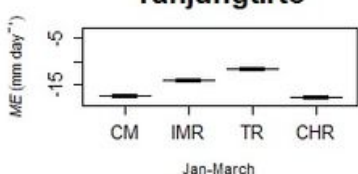

Tanjungtirto

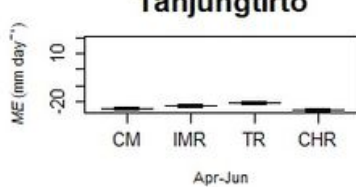

Tanjungtirto
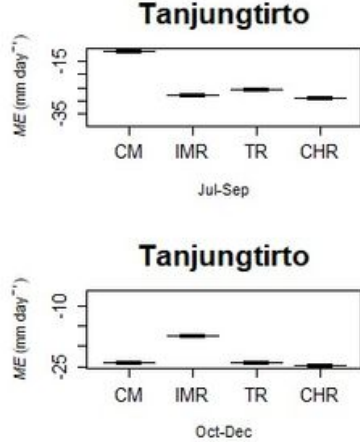

Bronggang

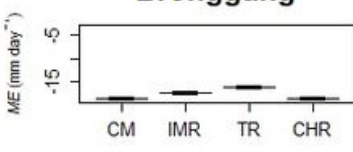

Bronggang

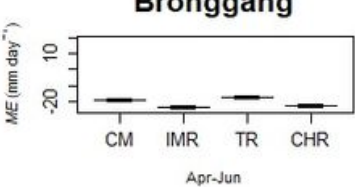

Bronggang
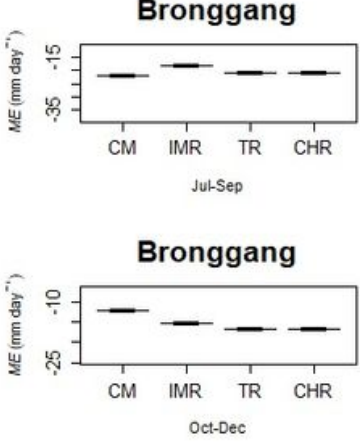

Kemput

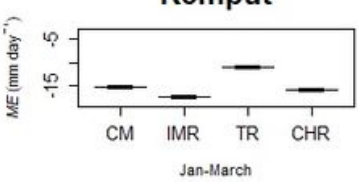

Kemput

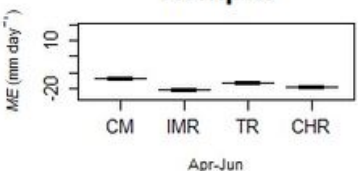

Kemput

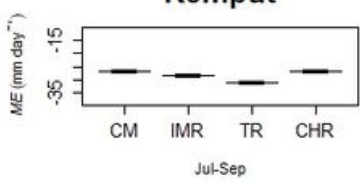

Kemput

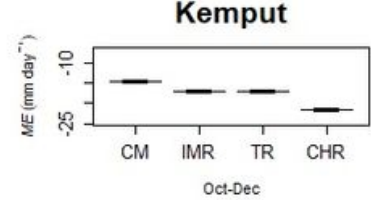

The boxplot of daily Mean Error (ME) of 4 satellite-based rainfall against 5 selected rain gauges for moderate rain from 1 January 2008 to December 2012

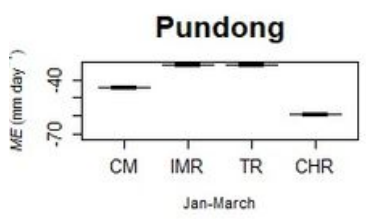

Pundong

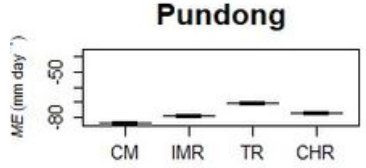

Apr-Jun

Pundong

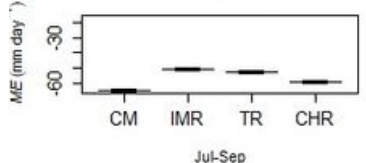

Pundong
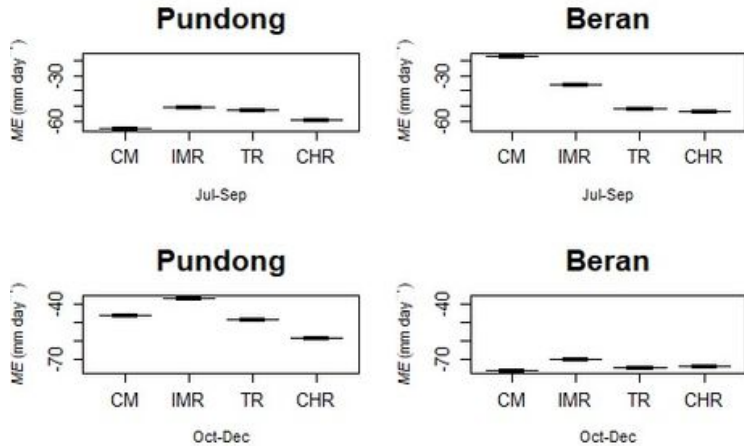

Beran
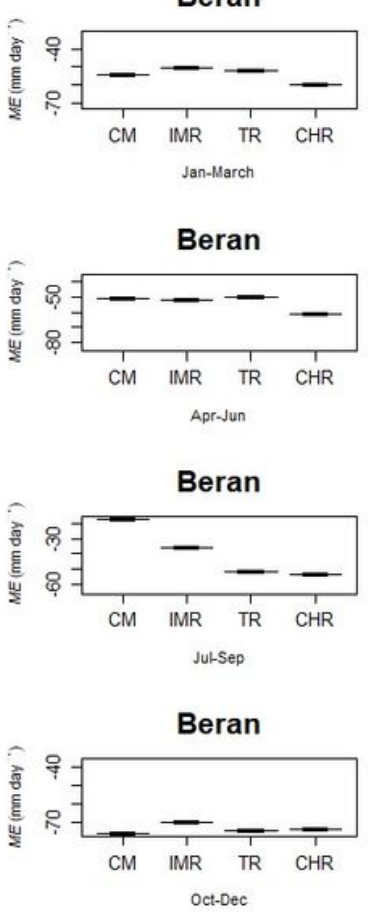

Beran

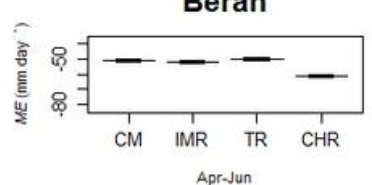

Beran

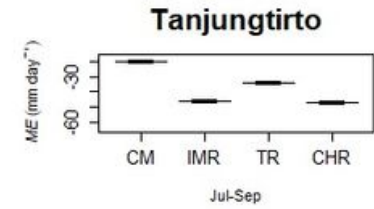

Tanjungtirto

Tanjungtirto
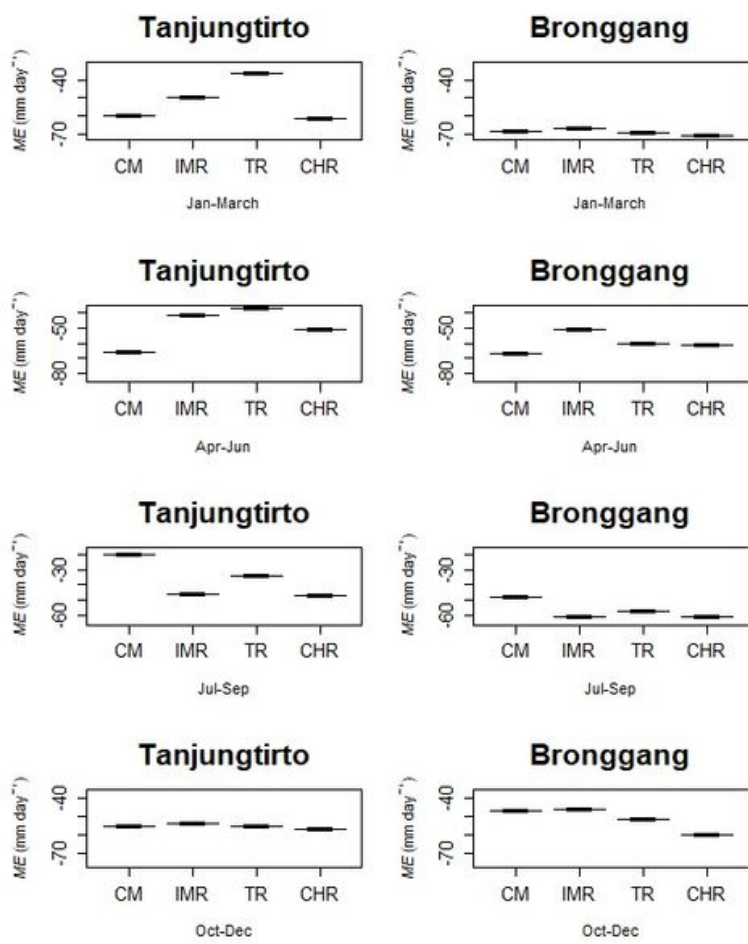

Bronggang
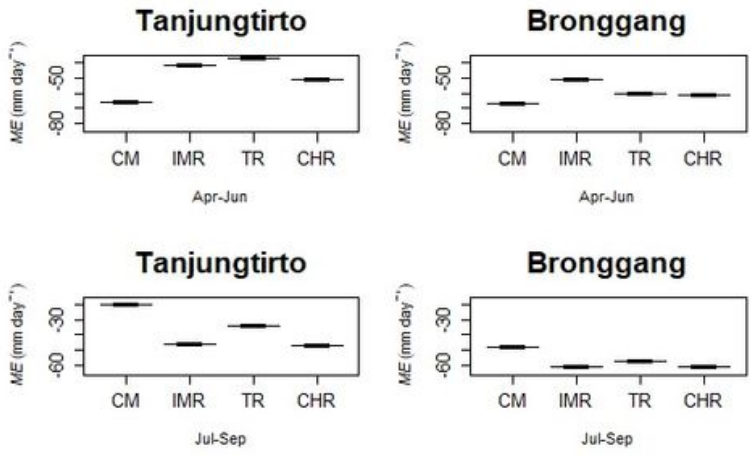

Bronggang

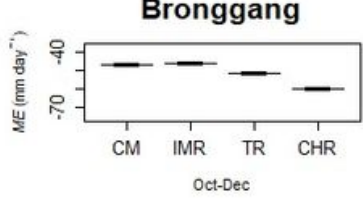

Kemput

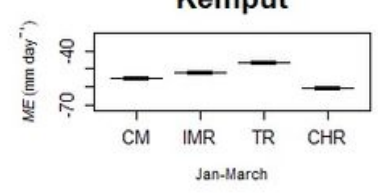

Kemput

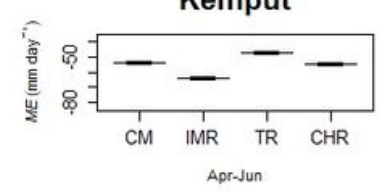

Kemput

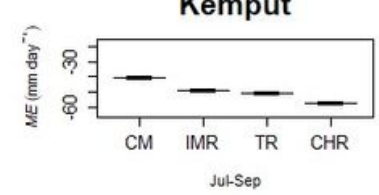

Kemput

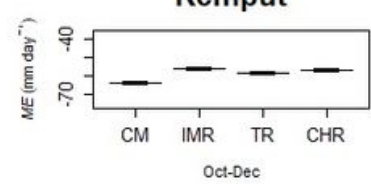

Figure 5 
The boxplot of daily Mean Error (ME) of 4 satellite-based rainfall against 5 selected rain gauges for heavy to extreme rain from 1 January 2008 to December 2012
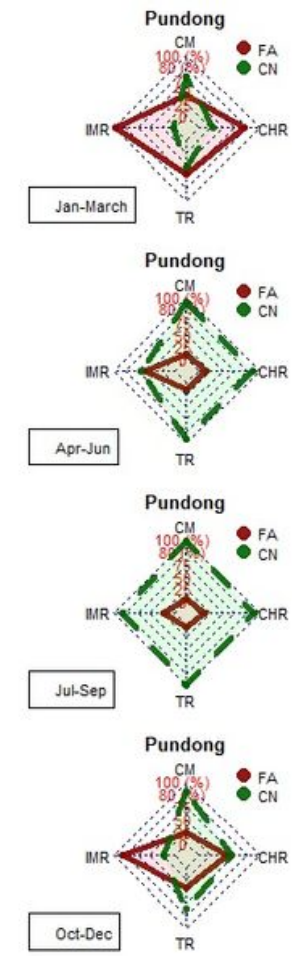
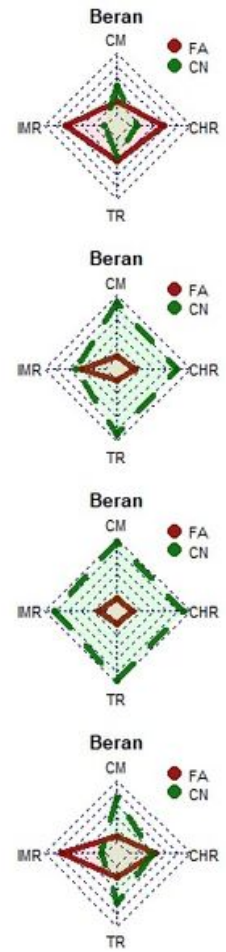
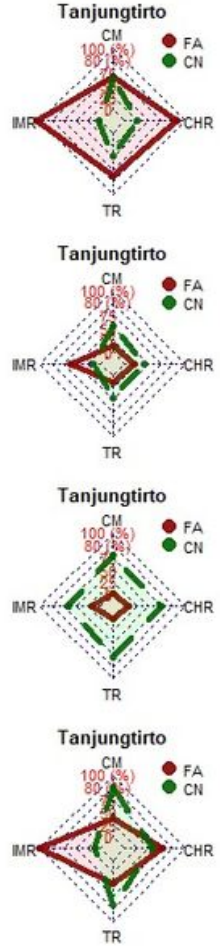
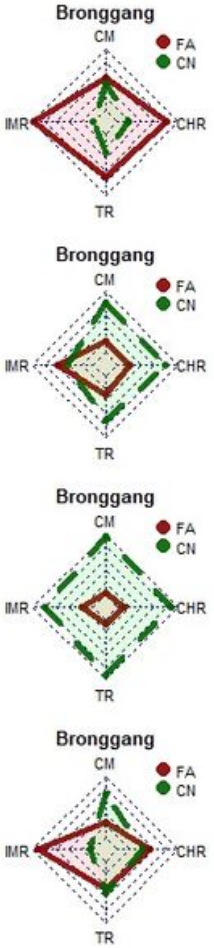
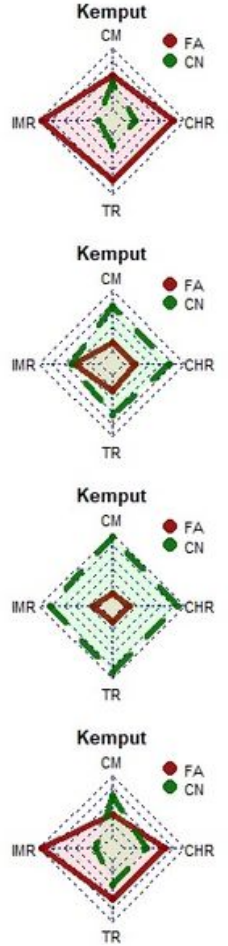

Figure 6

The radar chart of (FA and $\mathrm{CN}$ ) of 4 satellite-based rainfall against 5 selected rain gauges for rainfall intensity $0 \mathrm{~mm} \cdot$ day-1 (no rain) from 1 January 2008 to December 2012. The scale of radar chart is similar only for each season depending on minimum and maximum frequency values in each season
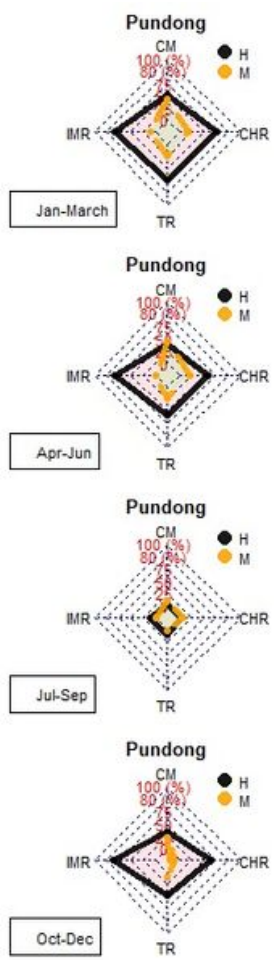
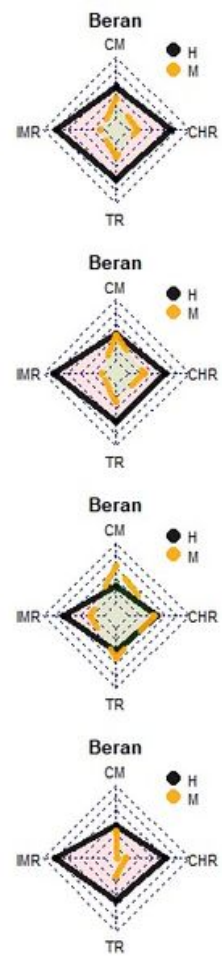
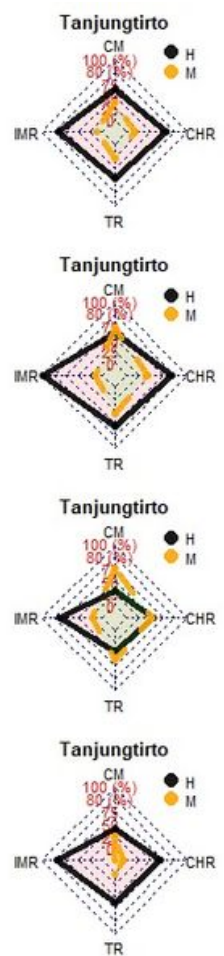
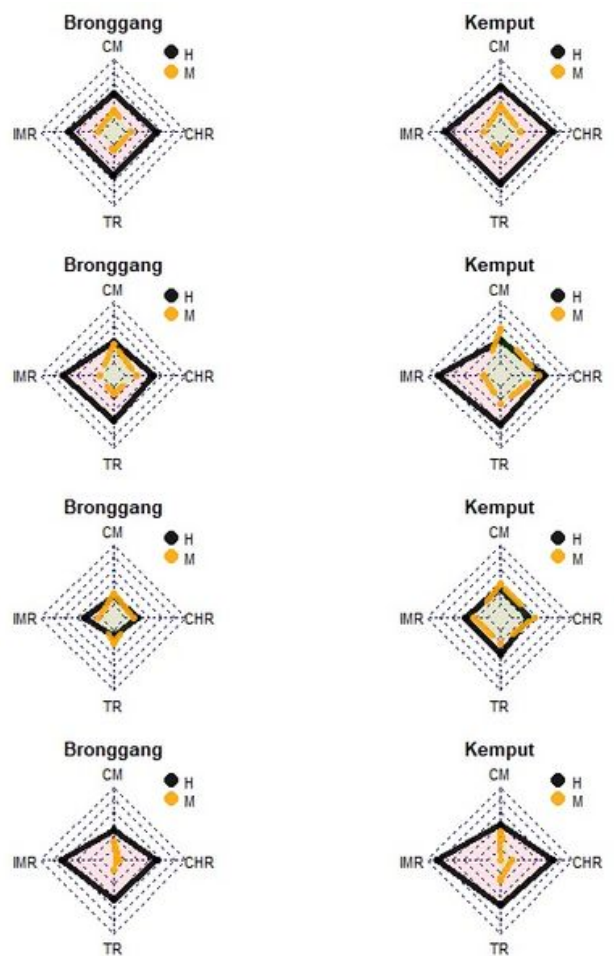
Figure 7

The radar chart of ( $\mathrm{H}$ and $\mathrm{M}$ ) of 4 satellite-based rainfall against 5 selected rain gauges for light rain from 1 January 2008 to December 2012. The scale of radar chart is similar only for each season depending on minimum and maximum frequency values in each season
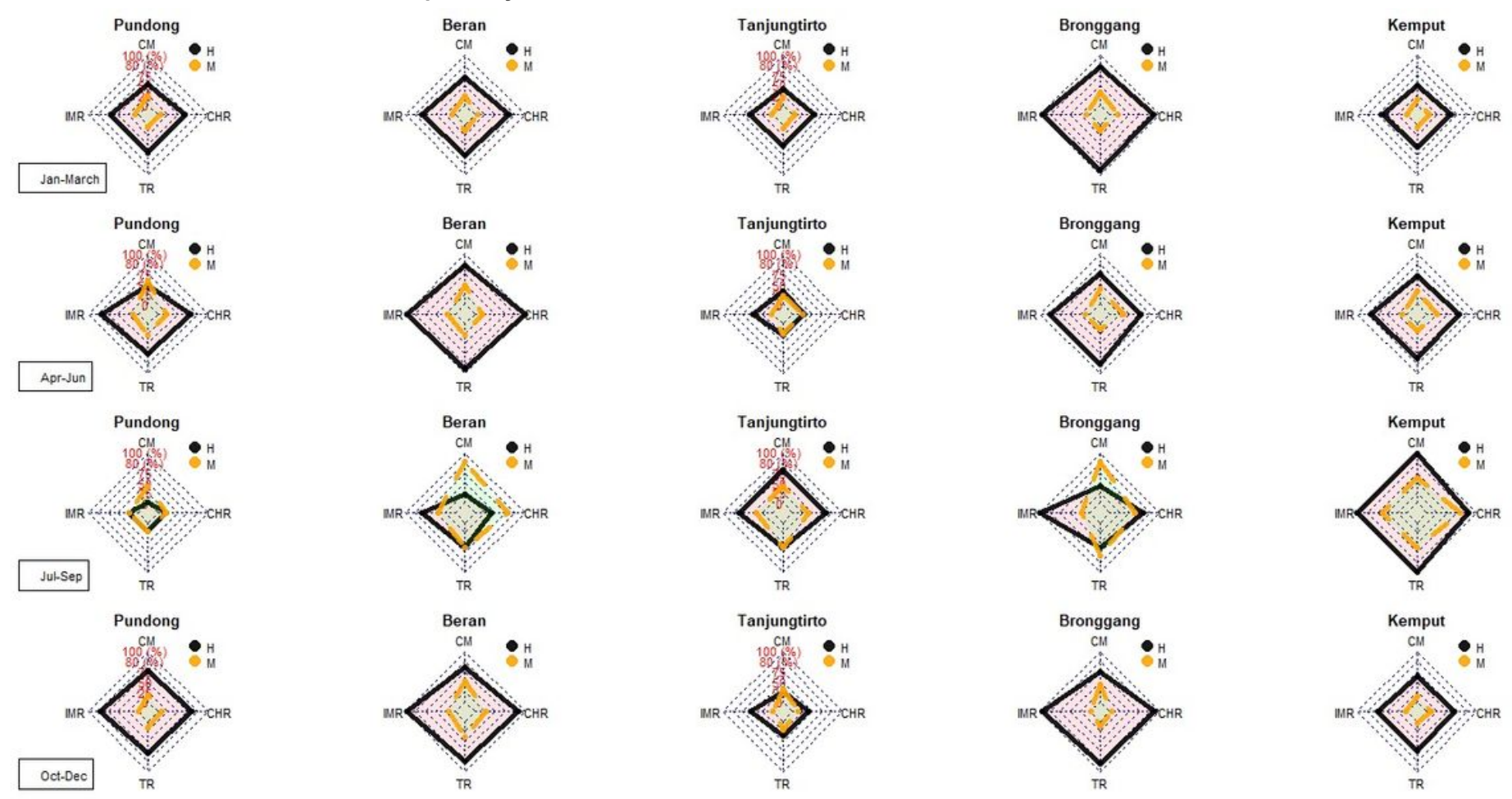

\section{Figure 8}

The radar chart of $(\mathrm{H}$ and $\mathrm{M})$ of 4 satellite-based rainfall against 5 selected rain gauges for moderate rain from 1 January 2008 to December 2012. The scale of radar chart is similar only for each season depending on minimum and maximum frequency values in each season 

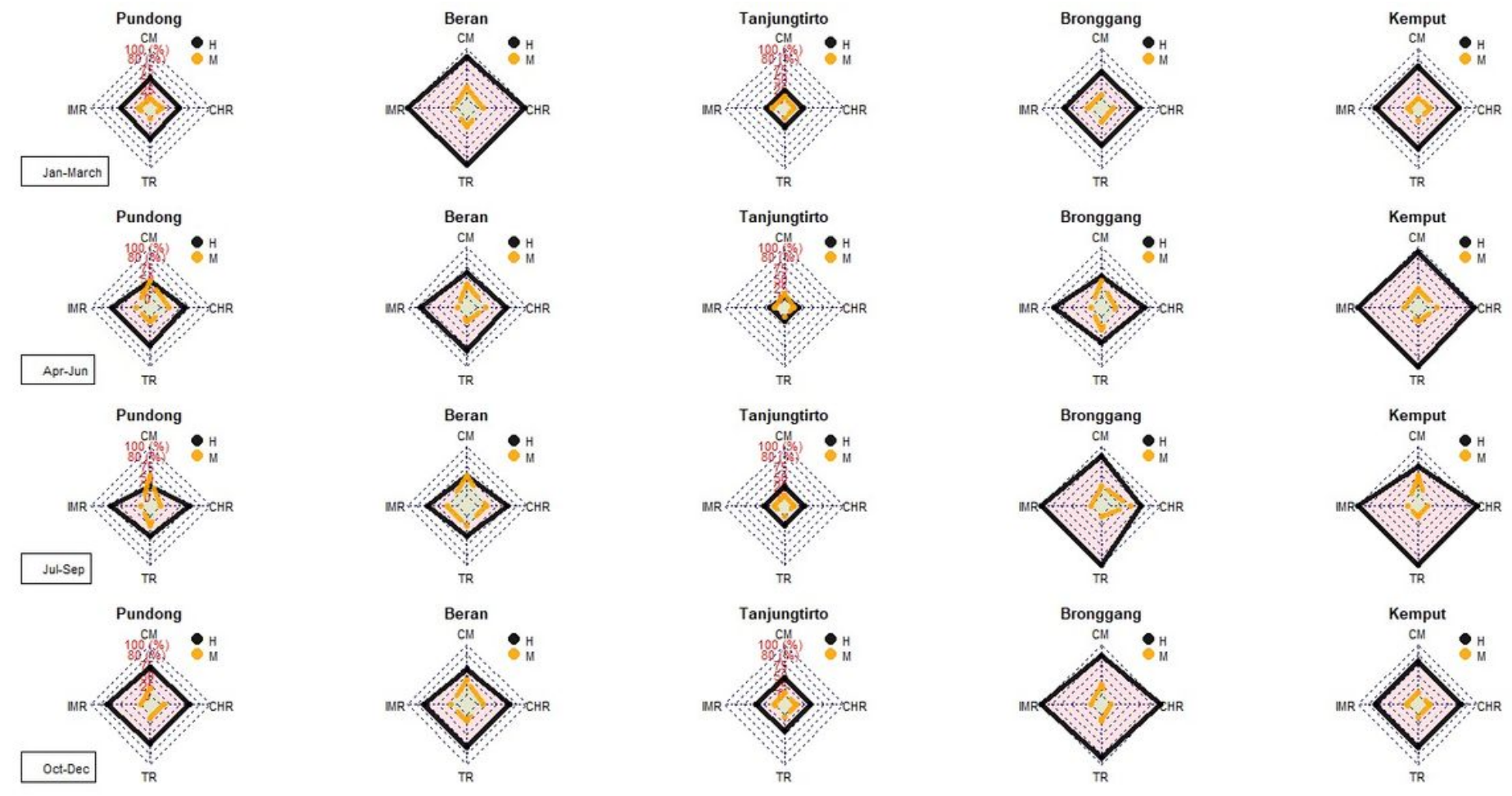

Figure 9

The radar chart of ( $\mathrm{H}$ and $\mathrm{M})$ of 4 satellite-based rainfall against 5 selected rain gauges for heavy to extreme rain from 1 January 2008 to December 2012. The scale of radar chart is similar only for each season depending on minimum and maximum frequency values in each season 


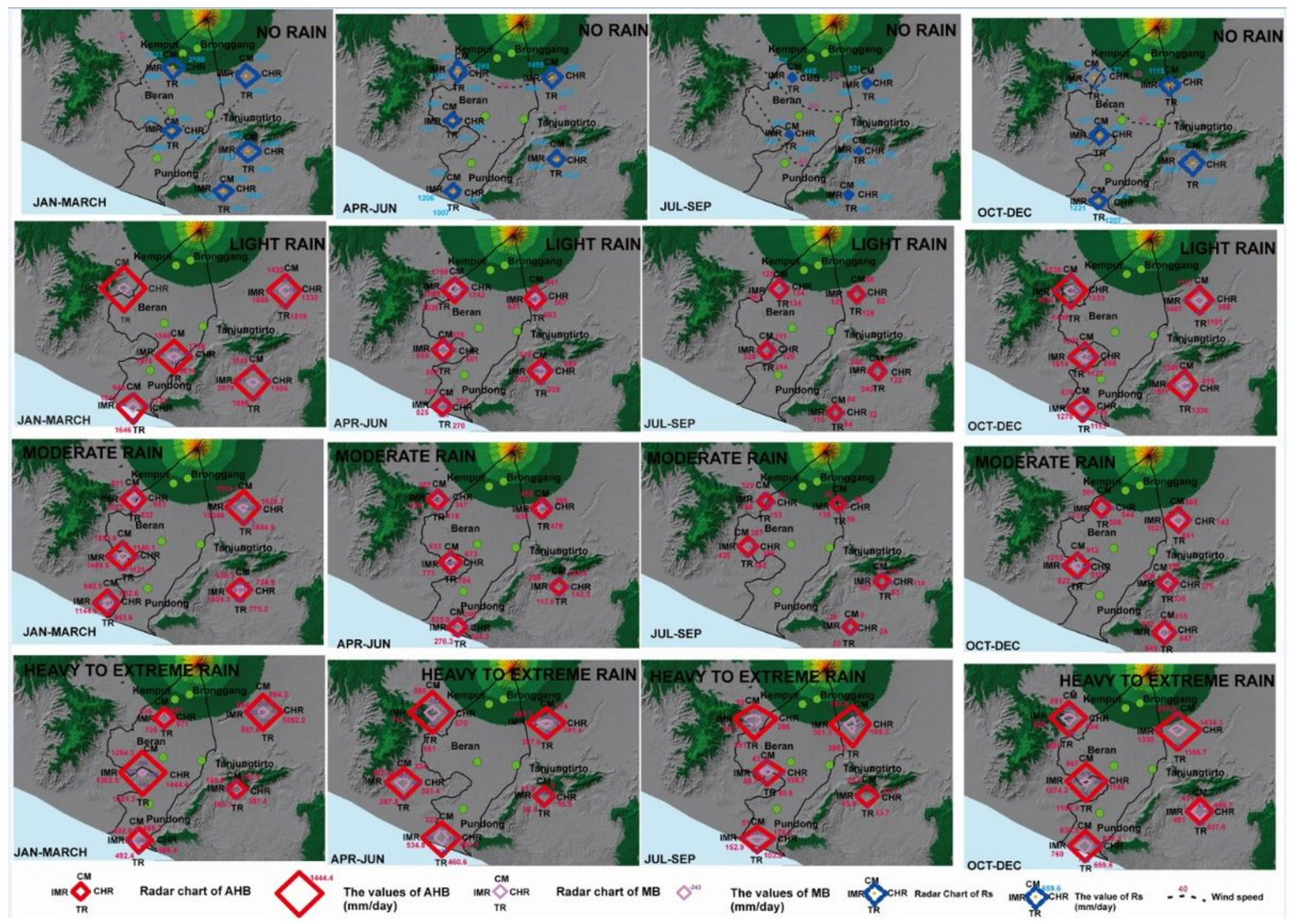

Figure 10

The spatial maps of radar chart of (Rs or TB) of 4 satellite-based rainfall for no rain and the spatial maps of radar chart of (MB and $\mathrm{AHB}$ ) of 4 satellite-based rainfall for light to extreme rain against 5 selected rain gauges from 1 January 2008 to December 2012

\section{Supplementary Files}

This is a list of supplementary files associated with this preprint. Click to download.

- Table1.xlsx

- Table2.xlsx

- Table3.xlsx

- Table4.xlsx

- Table5.xlsx

- Table6.xlsx 
- suplementarymaterial.docx

Page 26/26 